\title{
Predictive Analysis of Cognitive Errors of Control Room Operators: a Case Study in a Petrochemical Industry
}

\author{
Maryam Mosavi ghafarokhi1 $^{1 D}$, Davood Afshari1 ${ }^{\text {(D) }}$, Gholam abbas Shirali ${ }^{\text {* }}$ (D)
}

1. Departmenr of Safety and Occupational Health Engineering, Faculty of Public Health, Ahvaz Jundishapur University of Medical Sciences, Ahvaz, Iran

Article Info
Received: $2020 / 10 / 14 ;$
Accepted: $2020 / 12 / 28 ;$
ePublished: $2020 / 12 / 28$
dof $10.30699 /$ jergon.8.4.31
Use your device to scan
and read the article online
Q

Corresponding Author Gholam abbas Shirali Departmenr of Safety and Occupational Health Engineering, Faculty of Public Health, Ahvaz Jundishapur University of Medical Sciences, Ahvaz, Iran

Email: shirali@ajums.ac.ir

\section{ABSTRACT}

Background and Objectives: In recent decades, several major accidents have occurred in high-reliability industries such as petrochemical companies. Accident analysis shows that the occurrence of more than $90 \%$ of accidents in industries are due to human factor and only with technical-engineering measures and the establishment of safety rules and regulations can not be institutionalized safe behaviors in such industries. Therefore, despite a slight reduction in human presence in these industries, the potential for human error risks is still high. The aim of this study was to identify and assess human errors in a petrochemical plant using the technique for the retrospective and predictive analysis of cognitive errors (TRACEr).

Methods: The sample size was all the eight operators of control room working in four shifts. In the first step, all tasks were analyzed using the hierarchical task analysis in order to identify sub-tasks. Then, for all the subtasks, different error modes (external and internal), psychological error mechanism (PEM) and performance shaping factors (PSFs) were identified and recorded in TRACEr sheet.

Results: The analysis of TRACEr sheets indicated that of a total number of 1171 detected errors, the internal and external errors were $50.67 \%(n=593)$ and $49.33 \%$ $(\mathrm{n}=578)$, respectively. In this line, timing/sequence' errors with $35.36 \%$ and 'quality/selection' errors with $30.03 \%$ were identified as the highest and lowest external error modes, respectively. In classifying the internal error modes, action errors with $31.87 \%$ and decision making with $10.73 \%$ were identified as the highest and lowest external error modes, respectively. Within PEMs, distraction/preoccupation (23.61\%) was identified as the main causes of perception errors. The analysis of the PSFs shows that 'Organization' with $27.95 \%$ and 'task complexity' with $8.74 \%$ were two main factors affecting the task errors.

Conclusion: The current study could identify many of the errors and conditions that affect the performance of operators. Therefore, this study can be introduced as a basis for managers and stockholders of chemical industries with complexity and high risk in order to prioritize human error prevention programs.

Keywords: Cognitive error, TRACEr, External error mode, Internal error mode, PSM, PSF

Copyright (C) 2021, This is an original open-access article distributed under the terms of the Creative Commons Attribution-noncommercial 4.0 International License which permits copy and redistribute of the material just in noncommercial usages with proper citation.

\section{How to Cite This Article:}

Mosavi ghafarokhi M, Afshari D, Shirali GH. Predictive Analysis of Cognitive Errors of Control Room Operators: a Case Study in a Petrochemical Industry. Iran J Ergon. 2020; 8 (4) :31-49 


\section{Extended Abstract}

\section{Introduction}

So far, many studies have been performed using various methods such as SHERPA [19-23] CREAM [23, 24] and HEART [25] in petrochemical control rooms; however, studies based on technique for the retrospective and predictive analysis of cognitive errors (TRACEr) are very rare. Therefore, the aim of this study was to analyze human error in the control room using the TRACEr method. The reason for choosing this method in comparison with similar methods is related to the systematic nature of the error analysis process in this method, identifying the methodological mechanisms of error and the factors that shape the performance, which are considered as the strengths of this method; therefore, due to the supervisory and operational nature of the control room operator of the petrochemical industry and also the high workload, complexity of this section and the extent of the shaping and psychological factors of error, this study was conducted to analyze the predictive cognitive errors of control room operators in southwestern Iran.

\section{Methods}

The sample size was all the eight operators of control room working in four shifts. In the first step, all tasks were analyzed using the hierarchical task analysis in order to identify subtasks. Then, for all the subtasks, different error modes (external and internal), psychological error mechanism (PEM) and performance shaping factors (PSFs) were identified and recorded in TRACEr sheet.

Table 1. External error mode (EEM)

\begin{tabular}{|cc|}
\hline Modes & Error description \\
\hline $\begin{array}{c}\text { Quality and } \\
\text { selection }\end{array}$ & $\begin{array}{c}\text { Deleting a task, too much action, too little action, too little action, wrong direction, wrong } \\
\text { action on right goal, wrong action on wrong goal, wrong action on wrong goal, } \\
\text { unnecessary action }\end{array}$ \\
\hline $\begin{array}{c}\text { Scheduling and } \\
\text { sequencing }\end{array}$ & Too late, too early, too repetitive, too short, too long, too wrong \\
\hline $\begin{array}{c}\text { Exchange of } \\
\text { information }\end{array}$ & $\begin{array}{c}\text { Ambiguous transfer of information, ambiguous registration of information, lack of access } \\
\text { to information, non-transfer of information, non-registration of information, incomplete } \\
\text { transfer of information, incomplete registration of information, incorrect transfer of } \\
\text { information, incorrect registration of information }\end{array}$ \\
\hline
\end{tabular}

Table 2. Classification of internal state and psychological mechanism of error

Internal error mode

The psychological mechanism of error

Perception

\begin{tabular}{|cc|}
\hline Perception & Biased bias \\
\hline Lack of visual recognition & Spatial confusion \\
\hline Delayed hearing & Perceptual confusion \\
\hline Wrong reading & Defects in perceptual prioritization \\
\hline Visual misunderstanding & Perceptual tunneling * \\
\hline Misidentify & Saturation of stimuli \\
\hline Lack of identification & Lack of consciousness \\
\hline Delayed visualization & Attention / mental preoccupation \\
\hline Lack of auditory diagnosis
\end{tabular}


Auditory error

Delayed auditory hearing

\begin{tabular}{|cc|}
\hline Memory & Similar intervention \\
\hline Forget the task & Memory capacity saturation \\
\hline Futuristic memory impairment & Negative transmission \\
\hline Forgetting previous actions & Wrong learning \\
\hline Forget temporary information & Insufficient learning \\
\hline Wrong to recall temporary information & Memory freeze \\
\hline Incorrect recall of stored information & Attention / mental preoccupation \\
\hline
\end{tabular}

\begin{tabular}{|c|c|}
\hline Judgment, planning, decision making & False knowledge \\
\hline Wrong prediction & Lack of knowledge \\
\hline Poor decision making & Deficiency in considering long-term or side effects \\
\hline Delayed decision & Misunderstanding \\
\hline Make a decision & Cognitive stabilization \\
\hline Poor planning & Wrong assumption \\
\hline \multirow[t]{2}{*}{ No program } & Prioritization defect \\
\hline & Hesitant to make decisions \\
\hline Execution of action & Spatial confusion \\
\hline Selection error & The predominance of habit \\
\hline Position error & Perceptual confusion \\
\hline Time error & Functional confusion \\
\hline Unclear information transmitted & Improper accent \\
\hline Unclear recorded information & Thoughts leading to action \\
\hline Incorrectly registered information & Environmental interference \\
\hline Unreported information & Attention / mental preoccupation \\
\hline
\end{tabular}

Table 3. Performance shaping factors (PSF)

\section{Factors}

Instructions

\section{Description of the effect}

Are there any instructions? What is the clarity, complexity and number of instructions? 


\begin{tabular}{|c|c|}
\hline $\begin{array}{l}\text { Training and } \\
\text { experience }\end{array}$ & Do operators have the necessary training and experience to perform the task? \\
\hline Interaction & Is the human-machine interaction defined in a clear and logical way? \\
\hline Organization & $\begin{array}{c}\text { Are there enough operators to do the job? Communication system? Accountability and } \\
\text { teamwork? }\end{array}$ \\
\hline $\begin{array}{l}\text { Individual } \\
\text { characteristics }\end{array}$ & $\begin{array}{l}\text { Does the task require alertness, concentration and mental skills? Can the assigned task } \\
\text { cause fatigue and anxiety? }\end{array}$ \\
\hline $\begin{array}{l}\text { Complexity of the } \\
\text { task }\end{array}$ & Is the task entrusted with a lot of complexity? \\
\hline Environment & $\begin{array}{l}\text { Does the physical environment interfere with the performance of the assigned task? } \\
\text { Ambient lighting? Stunned by screen displays? High ambient temperature? }\end{array}$ \\
\hline
\end{tabular}

\section{Results}

The analysis of TRACEr sheets indicated that of a total number of 1171 detected errors, the internal and external errors were $50.67 \%(n=593)$ and $49.33 \% \quad(n=578)$, respectively. In this line, timing/sequence' errors with $35.36 \%$ and 'quality/selection' errors with $30.03 \%$ were identified as the highest and lowest external error modes, respectively. In classifying the internal error modes, action errors with $31.87 \%$ and decision making with $10.73 \%$ were identified as the highest and lowest external error modes, respectively. Within PEMs, distraction/ preoccupation $(23.61 \%)$ was identified as the main causes of perception errors. The analysis of the PSFs shows that "Organization" with 27.95\% and "task complexity" with $8.74 \%$ were two main factors affecting the task errors.

Table 4. Results of external error mode

\begin{tabular}{ccc} 
Modes & Frequency & $\%$ \\
\hline Quality and selection & 92 & 30.03 \\
\hline Scheduling and sequencing & 111 & 36.35 \\
\hline Exchange of information & 103 & 33.62 \\
\hline
\end{tabular}

Table 5. Results of internal error mode

\begin{tabular}{ccc|} 
Modes & Frequency & $\%$ \\
\hline Perception & 89 & 89.29 \\
\hline Memory & 82 & 51.27 \\
\hline Judgment, planning and decision making & 32 & 73.10 \\
\hline Performance & 95 & 87.31 \\
\hline
\end{tabular}

Variable

\begin{tabular}{|c|c|c|}
\hline \multirow{4}{*}{ Age } & Less than 30 years & 28 \\
\hline & Between 30 and 40 years & 49 \\
\hline & Between 41 and 50 years & 34 \\
\hline & More than 50 years & 13 \\
\hline Gender & Male & 79 \\
\hline
\end{tabular}




\begin{tabular}{ccc}
\hline & Female & 45 \\
\hline Work history & Less than 10 years & 36 \\
& Between 10 and 20 years & 53 \\
\hline
\end{tabular}

\section{Discussion}

According to the results, the share of external error state and internal error state are 50.67 and $49.33 \%$, respectively. Based on the results of external state error (Table 4), errors related to scheduling and sequencing with $36.35 \%$ were recognized as the most external state errors and information exchange error (33.62\%) and quality and selection $(30.03 \%)$ were in the next ranks.

The results of this study in the subsets of the internal error state showed that in the study, the most state errors in the field of quality and selection to eliminate a task $(14.70 \%)$, in the timing and sequence of very late action (23.95\%) and in the information exchange section, it is related to the wrong transfer of information $(6.86 \%)$.

The results of Table 5 on the internal state of operator error showed that performance errors with $31.87 \%$, perception with $29.86 \%$, memory with $27.51 \%$ and judgment, planning and decision making with $10.73 \%$, respectively, include the highest to lowest percentage of internal errors.

Based on a study by Corver and Aneziris, cognitive and memory errors were identified as the most important errors, respectively. These results are inconsistent with the results of the present study where they prioritize perception errors over performance and memory errors [33]. Halvani et al. in a study using the SHERPA technique and the risk of human error in the control room operators of the gas refining company, showed that the most obvious errors were functional and regulatory errors; according to their results, the functional errors were due to forgetfulness in doing work. This finding is consistent with the present study where the most memory errors were due to forgetting to perform an action [34].

The results of this study on the factors that shape the performance of operators showed that organizational factors with $27.95 \%$, task complexity with $26.88 \%$ and individual characteristics with $20.43 \%$ are the most important factors that shape the performance.

\section{Conclusion}

The current study could identify many of the errors and conditions that affect the performance of operators. Therefore, this study can be introduced as a basis for managers and stockholders of chemical industries with complexity and high risk in order to prioritize human error prevention programs.

\section{Acknowledgement}

This article is part of a research project with ethics code IR.AJUMS.REC.1399.504. The Honorable Vice Chancellor for Research and Technology of Jundishapur University of Medical Sciences is hereby thanked. Also, thanks to all participants in this study.

\section{Conflict of Interest}

The authors declared no conflict of interest. 


\section{مقاله يخووهشى}

\section{تجزيلوتحليل ييشبينانة خطاهاى شناختى إيراتورهاى اتاق كنترل (مطالعة موردى در صنعت پيتروشيمى)}

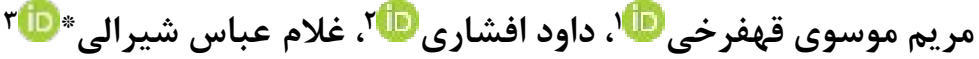

ا . دانشجوى كارشناسى ارشد مهندسى ايمنى و بهداشت كار، كروه مهندسى ايمنى و بهداشت كار، دانشكدة بهداشت، دانشعاه علوم يزشكى جندىشايور اهواز، اهواز، ايران

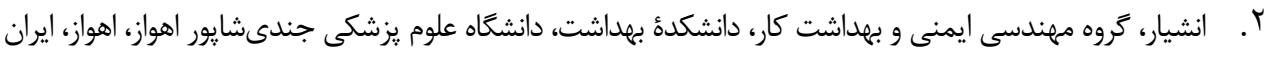

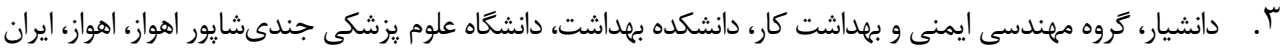

\begin{tabular}{|c|c|}
\hline 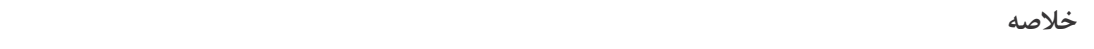 & 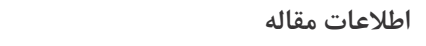 \\
\hline زمينه و هدف: در دهdهاى اخير، هندين حادثه بز بزرى در صنايع با قابليت اطمينان بالا مانند شركت & 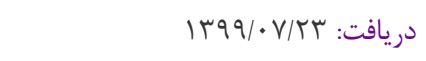 \\
\hline هاى يتروشمى رخ داده است. بررسى حوادث نشان مى دهد كه وقوع بيش از •9 درصد حوادث در صنايع & 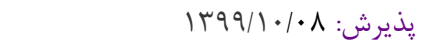 \\
\hline به عامل انسانى وابسته است و فقط با اقدامات فنى - مهندسى و وضع قوانين و مقررات ايمنى نمى توان & 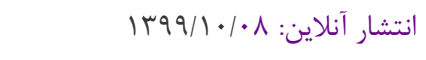 \\
\hline رفتارهاى ايمن را در صنعت نهادينه كرد و عليرغم كاهش كمى حضور انسان در اين صنايع، هنوز يتانسيل & \\
\hline وقوع خطرات ناشى از خطاهاى انسانى، بالا مى باشد. مطالعه حاضر با هدف شناسايى و ارزيابى پيشبينانه & نويسندهُ مسئو \\
\hline خطاهاى شناختى ايراتورهاى اتاق كنترل يكى از صنايع پتروشيمى انجام گرفت. & غلاد \\
\hline روش كار: در اين مطالعه كه در سال وqجا انجام شد، تمام ايراتورهاى اتاق كنترل يكى از صنايع يتروشيمى & 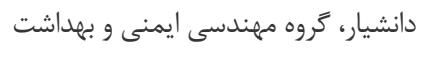 \\
\hline مناطق جنوبى كشور كه هشت نفر بودند و در جهار شيفت كار مىكردند، بررسى شدند. ابتدا وظايف با استفاده & 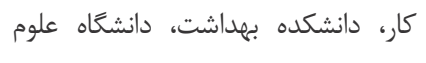 \\
\hline از آناليز سلسلهمراتبى به زيروظايف تفكيك شدند. سيس براى همهٔ زيروظايف، حالتهاى مختلف خطا (بيرونى & 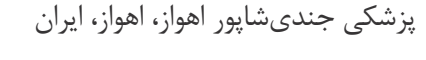 \\
\hline و درونى)، سازوكارهاى روانشناختى خطا و عوامل شكل دهنده عملكرد شناسايى شد. & يست الكتر \\
\hline يافته ها: آناليز وظايف و تجزيهوتحليل خطاها نشان مىدهد، از مجموع IVI خطاى شناسايىشده، سهمم & shirali@ajums. \\
\hline 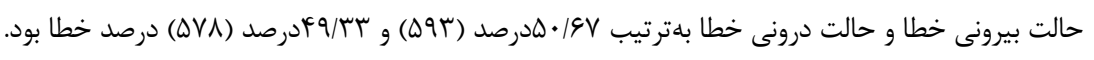 & \\
\hline برايناساس، خطاهاى مربوط به "زمانبندى و توالى" با ذس// سادرصد و خطاهاى "كيفيت و انتخاب" با & \\
\hline ץ •/•آدرصد بهترتيب بهعنوان بيشترين و كمترين خطاهاى حالت بيرونى مشخص شدند. در دستهبندى & \\
\hline خطاهاى حالت درونى، خطاهاى مربوط به 》اجرا《 با AV/ آسرصد بيشترين و خطاهاى "تصميمخيرى" با & براى دانلر \\
\hline rVT• ادرصد كمترين مقدار را به خود اختصاص دادند. در ميان مكانيسم روانشناختى خطا، "احواسيرتى| & S. كندي \\
\hline مشغوليت ذهنى" با |و/بrدرصد بيشترين مقدار را داشتند. دربارة فاكتورهاى شكلدهندهٔ عملكرد نيز & \\
\hline 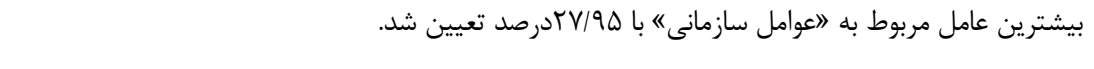 & 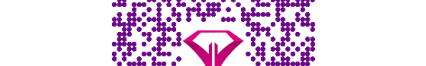 \\
\hline نتيجه كَيرى: در مطالعهُ حاضر، بسيارى از خطاها و شرايطى كه بر عملكرد ايراتورها تأثيركذار بود، شناسايى & the \\
\hline شد. درنتيجه، اين مطالعه مىتواند مبنايى براى مديران و صاحبان صنايع با ٍِيجيدگى و ريسك بالا مانند & \\
\hline صنايع شيميايى، بهمنظور اولويتبندى برنامههاى يِيشيرى از خطاى انسانى معرفى شود. & \\
\hline كليدوازهها: خطاى شناختى، TRACEr، حالت بيرونى خطا، حالت درونى خطا، مكانيسم روانشناختى و & \\
\hline عوامل شكلدهنده خطا & \\
\hline
\end{tabular}

مقدمه

[1 []؛ بهطورى كه در بيشتر فرايندها از فناورىهاى بيشرفته، مانند طراحى بهكمى كامييوتر، كاربرد ربات و كنترل عددى استفاده شده است. با افزايش سيستم اتوماسيون، بيشتر فرايندهاى عملياتى، بdدنبال انقلاب صنعتى و توسعهُ روزافزون دانش بشرى، كارها

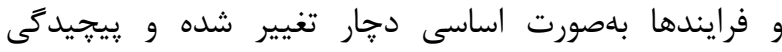
سيستمها در صنايع و سازمانهاى مختلف افزايش يافته است 
انسان در اين صنايع، هنوز زمينهُ وقوع خطرات ناشى از خطاهاى

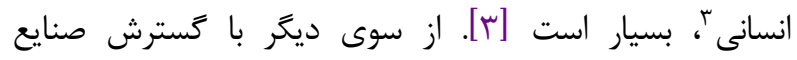

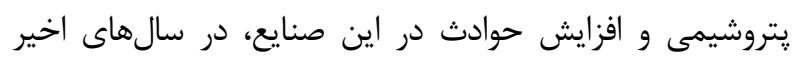

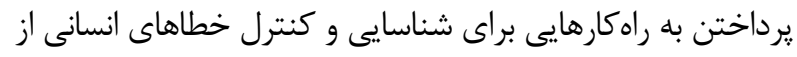

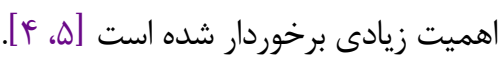

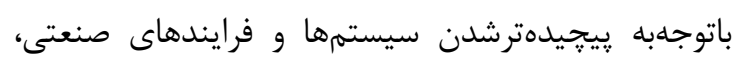

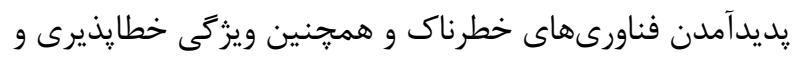
غيرقابل ييشبينى بودن انسان و اينكه يِيامد ناشى از اعمال انسانى

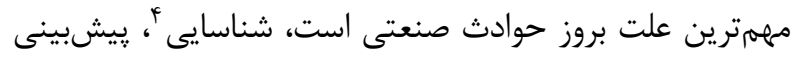

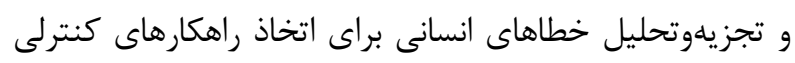

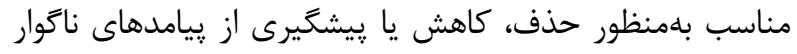

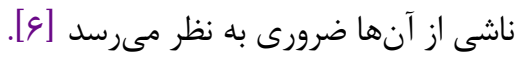

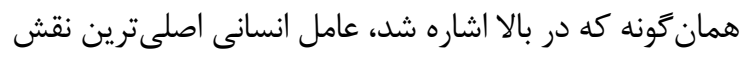

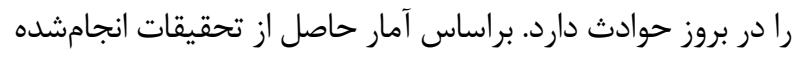

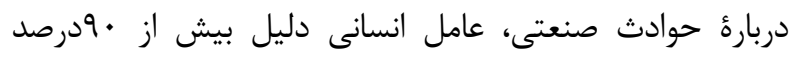

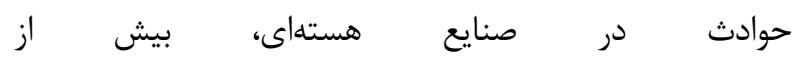

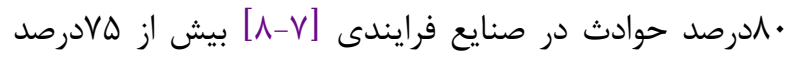

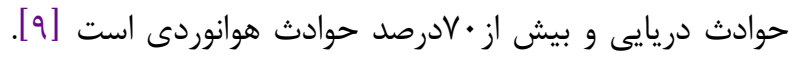

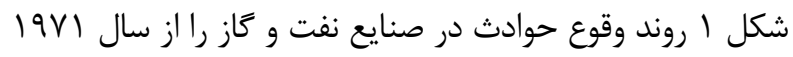

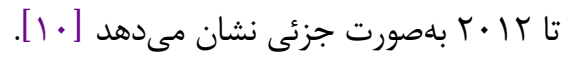

مانند صنايع شيميايى، يتروشيمى، هستهاى، يزشكى و نظامى

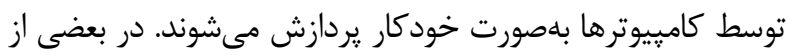

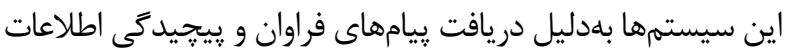
در سيستمهاى كامييوترى، سبب ايجاد نيازهاى شناختى و فعاليتهاى تشخيصى قابلتوجه براى ايراتورها مىشود كه مى إتواند

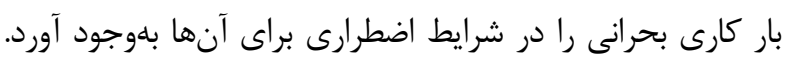

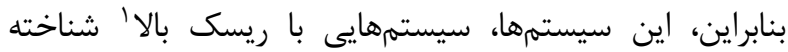
مىشوند. برايناساس، درصورت ايجاد نقص در يكى از اجزاى اين

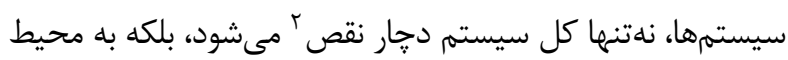

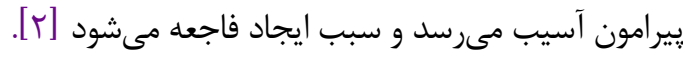
باوجود تلاشهايى كه براى ارتقاى ايمنى در صنايع و كاهش

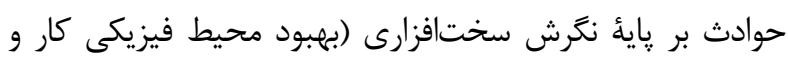

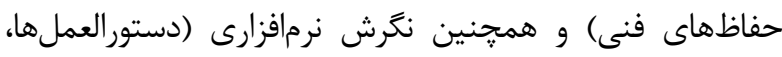

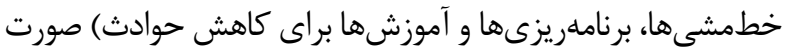

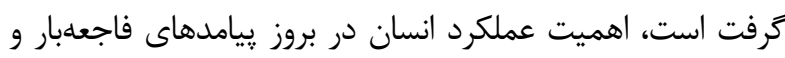
كاهى جبرانايذير حوادث كاهش نيافته است.

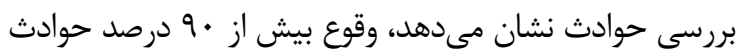

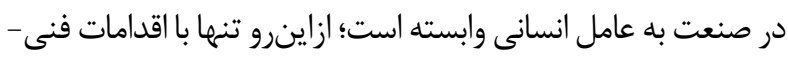

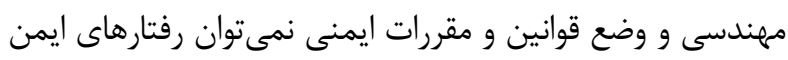
را در صنعت نهادينه كرد. همجنين باوجود كاهش كمى حضور

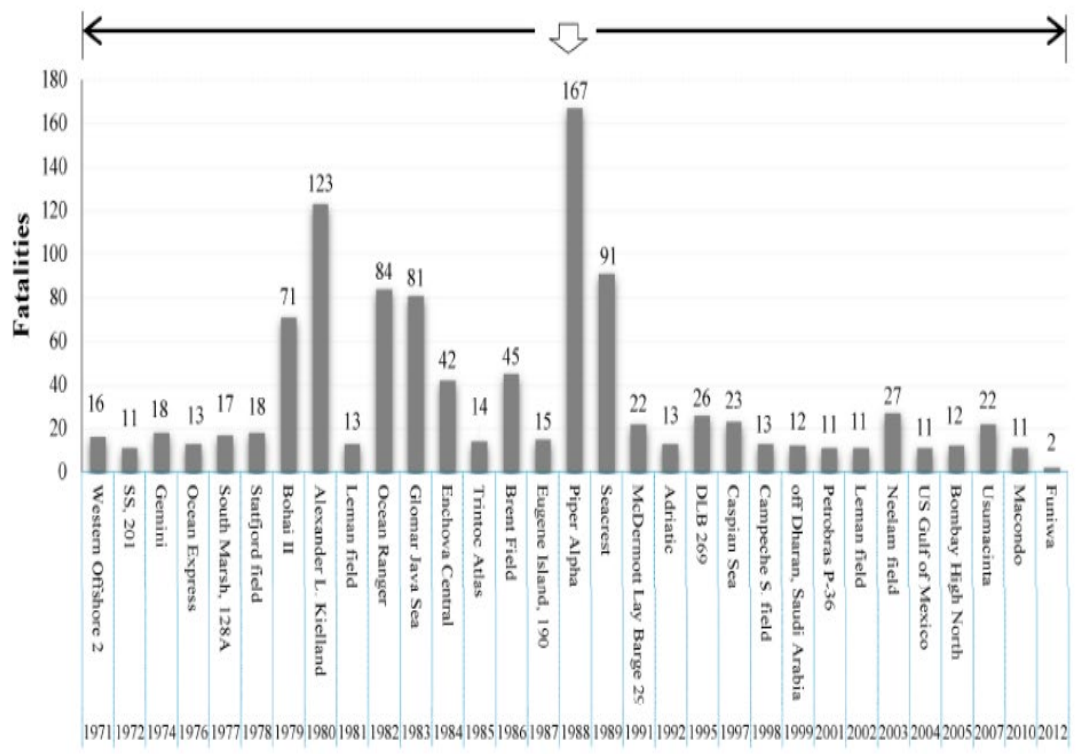

Years

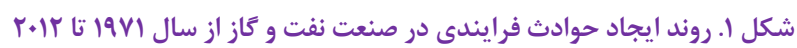

${ }^{3}$ Humans errors
${ }^{4}$ Identification
${ }^{1}$ High risk

${ }^{2}$ Fail 
كمياب است. بنابراين، هدف از اين مطالعه، تجزيهوتحليل خطاى

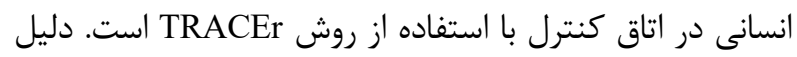

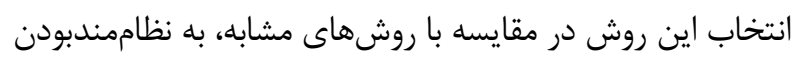

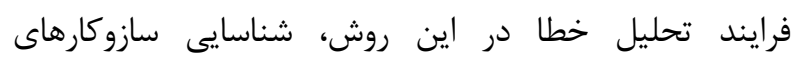

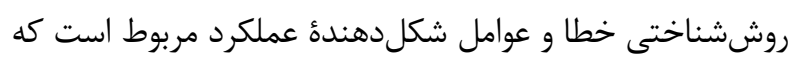

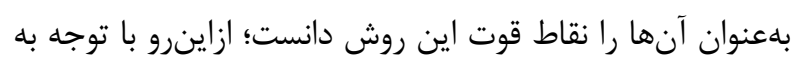

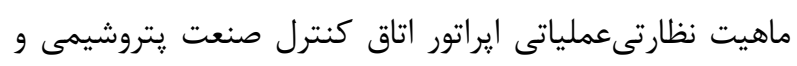

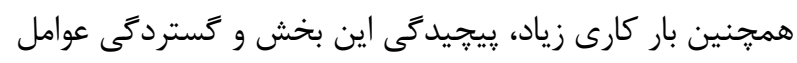

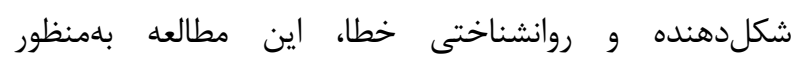

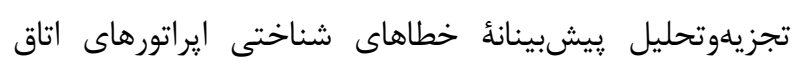
كنترل يكى از صنايع يتروشيمى جنوب غرب ايران انجام شد.

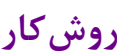

مطالعُ حاضر، مطالعهاى موردىمقطعى است كه در سال

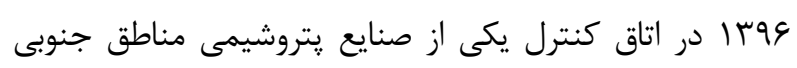

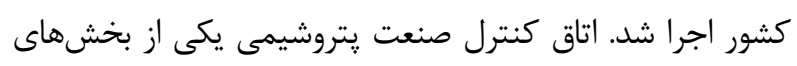

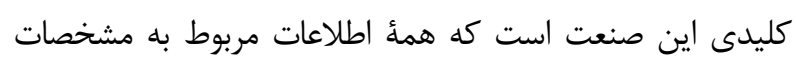

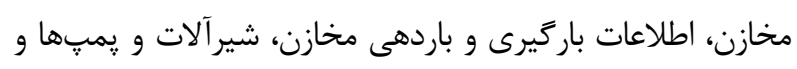

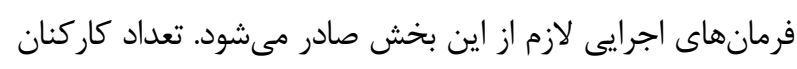

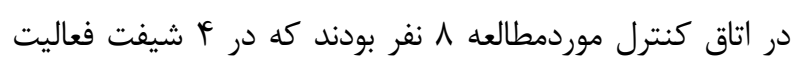
مىكردند. در هر شيفت يك نفر بهعنوان سرشيفت و يكى نفر نيز

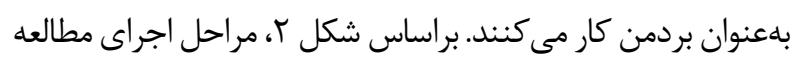

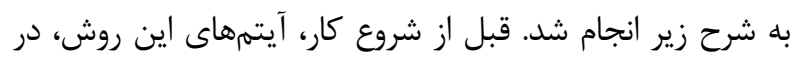

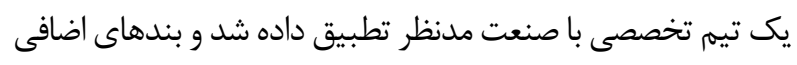

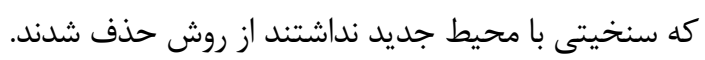
مرحلة اول: شناسايى وظايف شغلى: در اين مرحله، وظايف

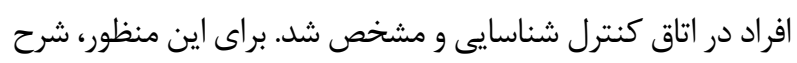

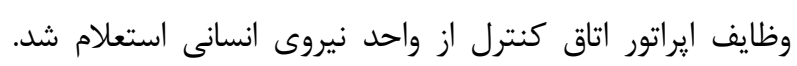

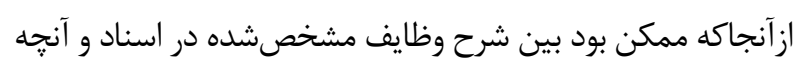

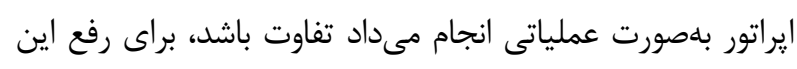

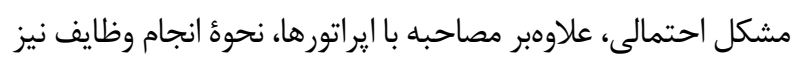

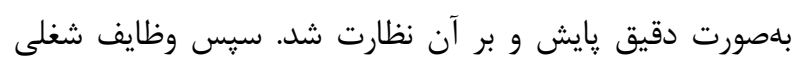

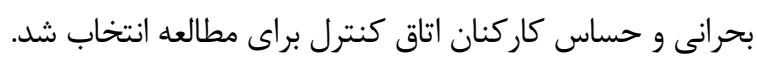

\footnotetext{
${ }^{6}$ Human Error Identification in Systems Tool

${ }^{7}$ Technique for the retrospective and predictive analysis of cognitive errors

${ }^{8}$ Hierarchical Task Analysis
}

براى شناسايى خطرات و ارزيابى ريسكها' روشهاى

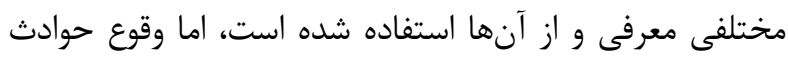

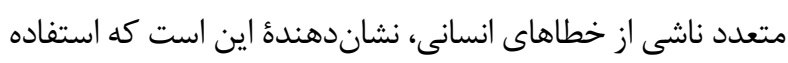

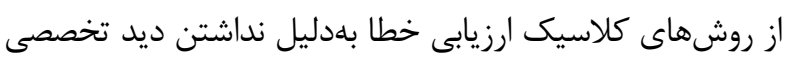

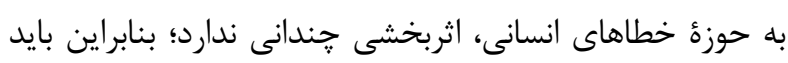

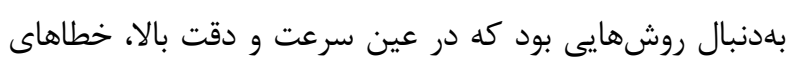

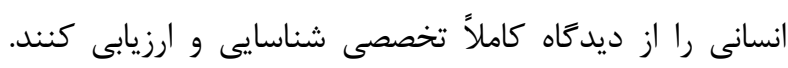

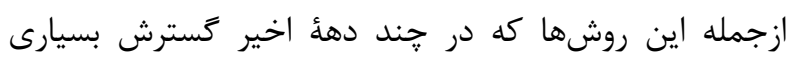

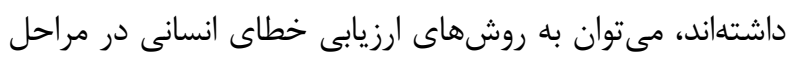

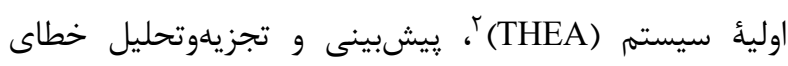

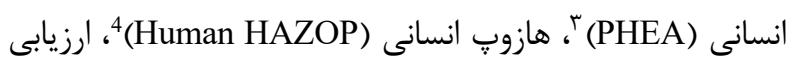

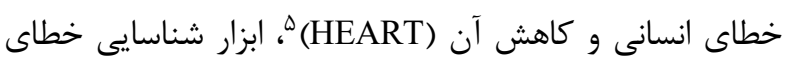

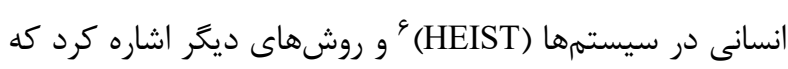

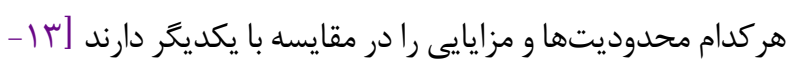

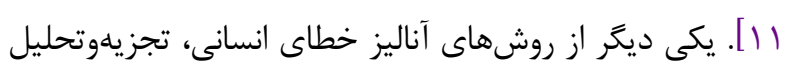

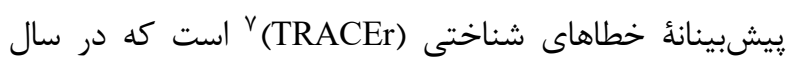

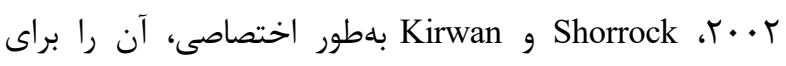

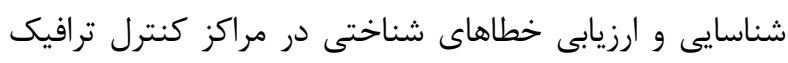

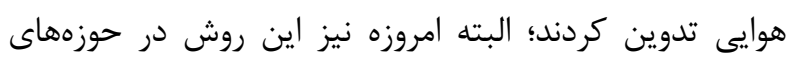

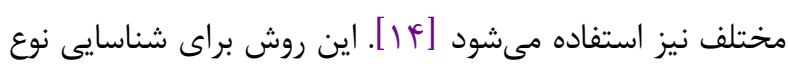

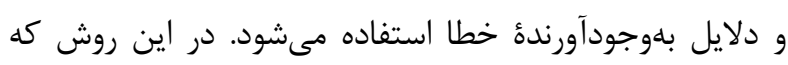

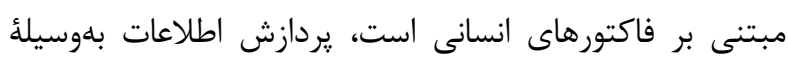

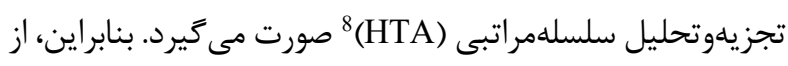

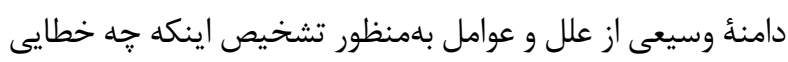
رخ مى دهد و علت آن جيست، استفاده مى كند.

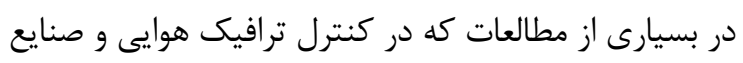

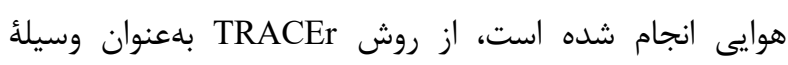

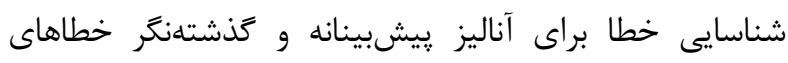

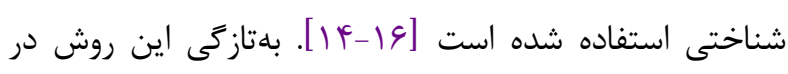

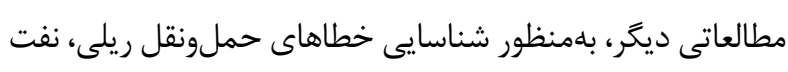

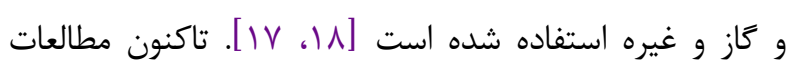

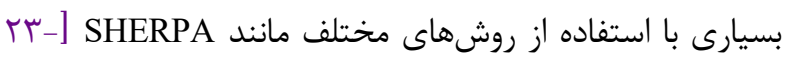

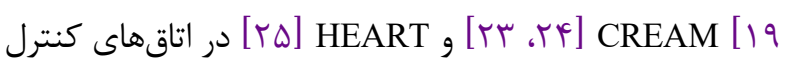
يتروشيمى انجام شده است، اما مطالعئ مبتنى بر اين روش بسيار

\footnotetext{
${ }^{1}$ Risk Assessment

2 Technique for Human Error Assessment

${ }^{3}$ Predictive Human Error Analysis

${ }^{4}$ Human Hazard and Operability Study

${ }^{5}$ Human error assessment and reduction technique
} 
جدول ا تقسيمبندى حالت بيرونى خطا ارائه شده است. براى

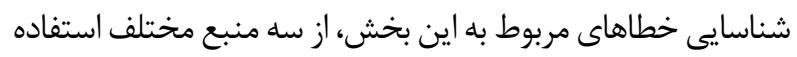

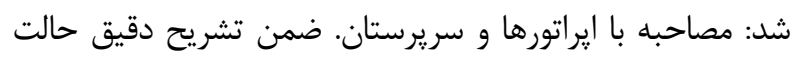

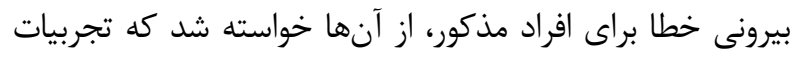

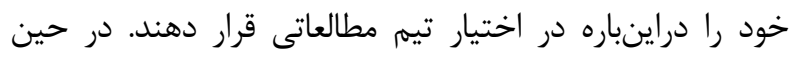

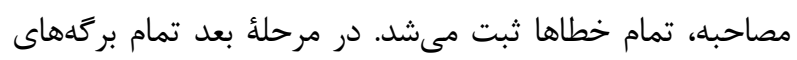

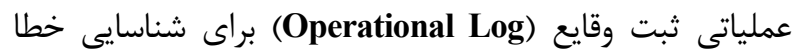
بررسى شد و درنهايت نيز بررسى و تحليل كزارش وفايع (باى ثبت حوادث

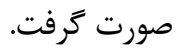

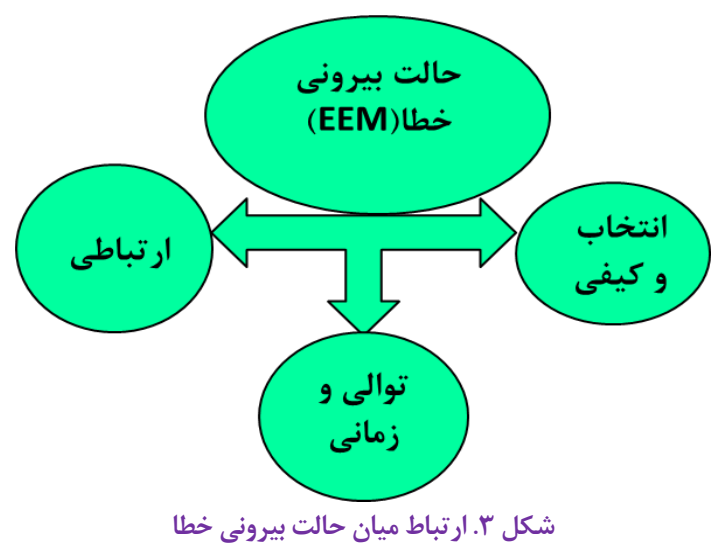

\section{حالت بيرونى خطا}

\section{مرحلة جههارم: حالت درونى خطا (IEM)': در اين مرحله،}

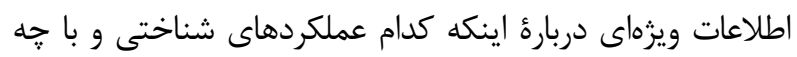

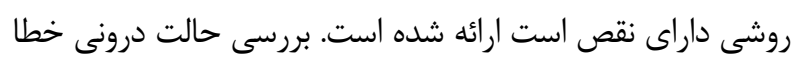

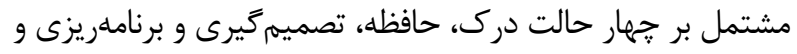

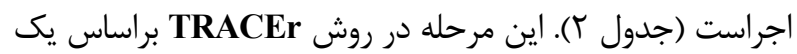

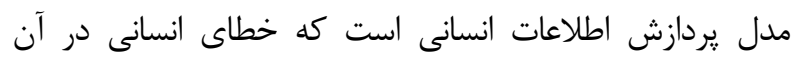
بلعنوان يك نقص در يردازش اطلاعات انسانى ديده شده و با مدل Wickens

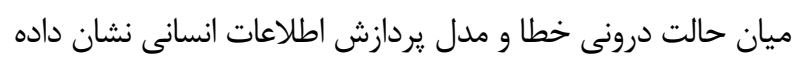

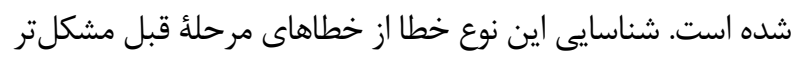
است. براى اين منظور يكى از راهكارهاى مؤثر براى شناسايى اين

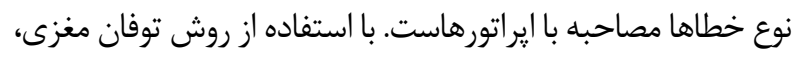

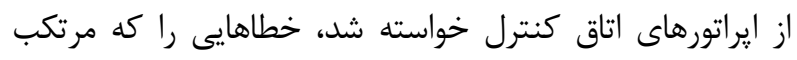
شدهاند يا احتمال دارد در حين كار مرتكب شوند، يادداشت كنند.

${ }^{2}$ Internal Error Mode

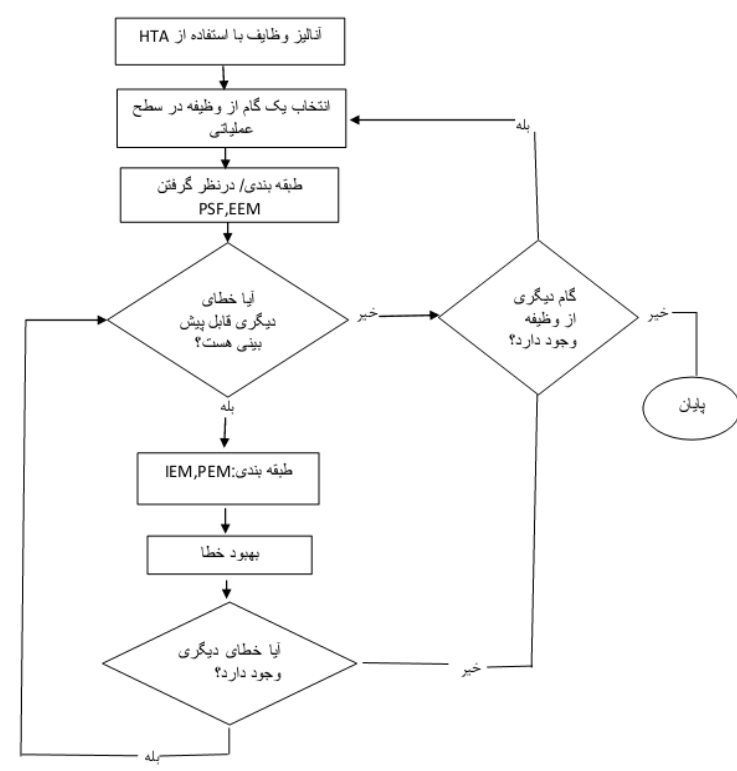

شكل r. فرايند اجراى تكنيك TRACEr

مرحلهُ دوم: تجزيهوتحليل وظايف شغلى: در اين مرحله،

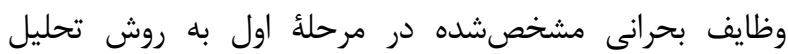
سلسهمراتبى (HTA) تجزيهوتحليل شد و زيروظيفههاى وظايف

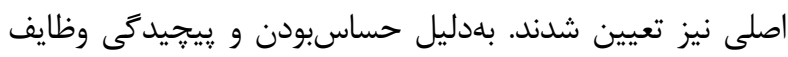
موردمطالعه، از روش مشاهده و مصاحبه با كارشناسان مجرب، براى بردي

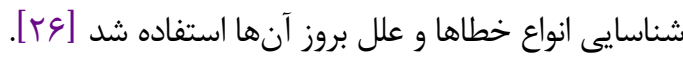
مرحلهُ سوم: حالت بيرونى خطا (EEM)': حالت بيرونى

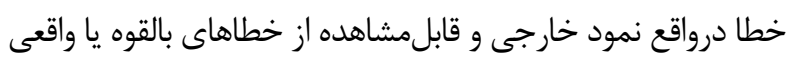

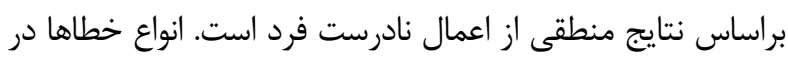
اين حالت، به سه دستأ خطاهاى كيفيت و انتخاب، خطاهاى زمانبندى و توالى و خطاهاى تبادل اطلاعات تقسيم مىشوند

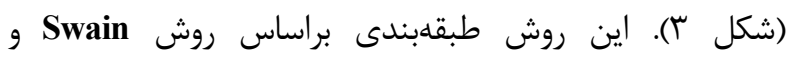
Guttmann سوم، خطاهاى بيرونى مربوط به فعاليتهاى تبادل اطلاعات

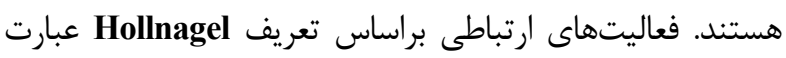
است از: تبادل اطلاعات موردنياز بين افراد و سامانه بهصورت كلامئي،

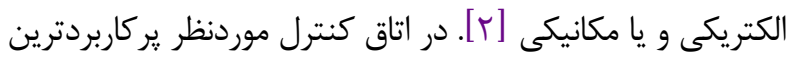

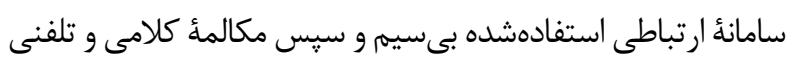

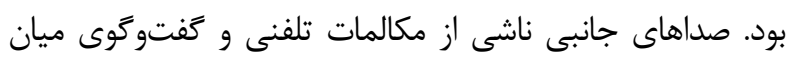

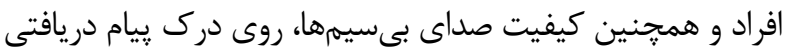

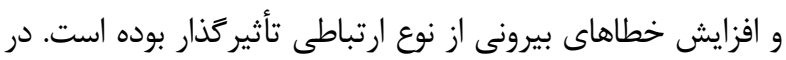


هر خطاى درونى بيان شده است. عوامل روانشناختى مانند

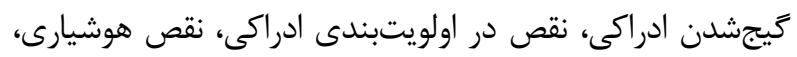

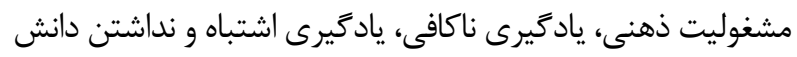

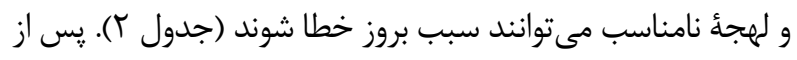

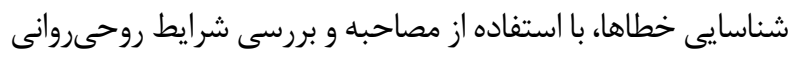

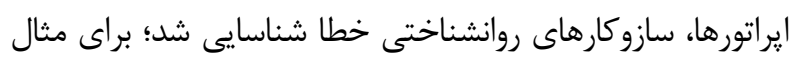

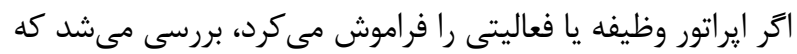

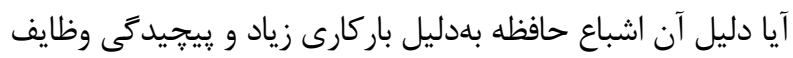

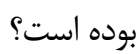

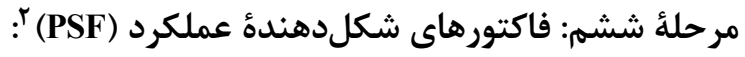

در اين مرحله، فاكتورهاى شكل ثيرى عملكرد ارزيابى شدند.

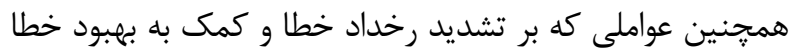

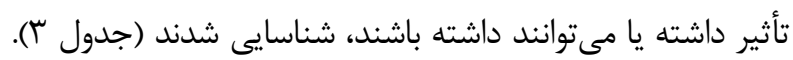
براى تعيين عوامل شكل دهنده عملكرد، ضمن مصاحبه با ايراتورها از روش بررسى محيط عملياتى إراتورها و امكانات و تجهيزات سختافزارى و نرمافزارى آنها استفاده شد.

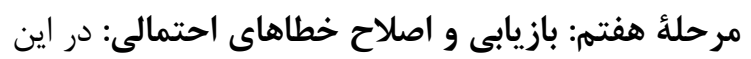

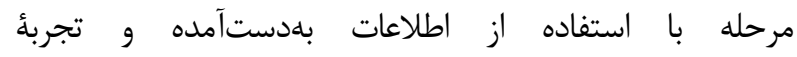
مشاركت كنندًان در تحقيق، توصيههايى كاربردى براى كاهش خطاها به صنعت موردمطالعه ارائه شد. توند
اين فرايند در هندين جلسه تكرار شد. سيس تيم تخصصى با توجه

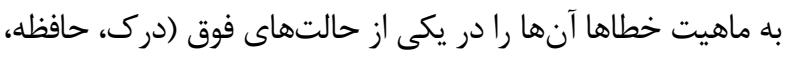

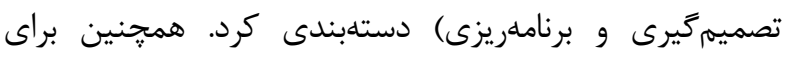
شناسايى تكميلى از بررسى كزارشهاى حوادث استفاده شد.

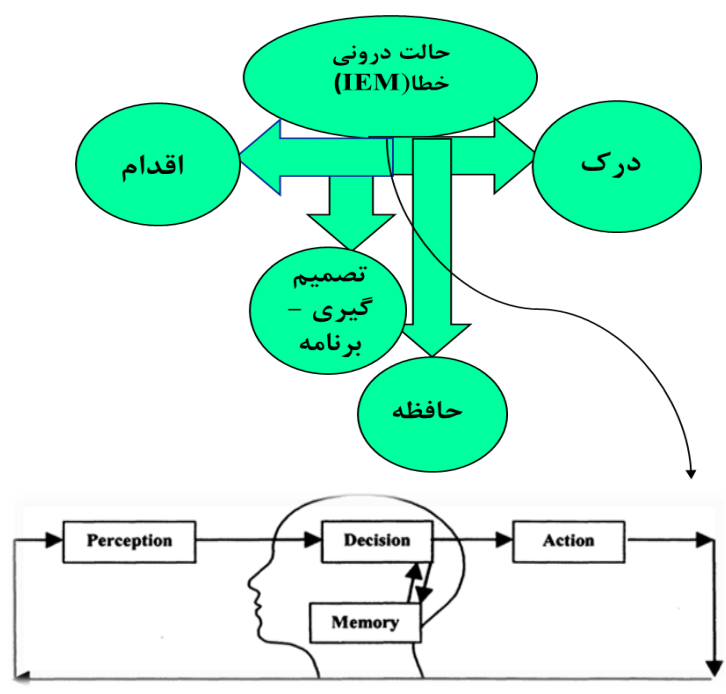

شكل F. ارتباط حالت درونى خطاو مدل يردازش اطلاعات انسانى

مرحلهُ هنجمم: مكانيسم روانشناختى خطا (PEM)!: در اين مر حله، مكانيسم روانشناختى خطا و دلايل روانشناختى براى وقوع

جدول ا. حالت بيرونى خطا (EEM)

\section{توصيف خطا}

حالتها

حذف يك وظيفه، اقدام بسيار زياد، اقدام بسيار كم، اقدام در جهت اشتباه، اقدام اشتباه در هدف درست، اقدام درست در هدف اشتباه، اقدام اشتباه در هدف اشتباه، اقدام غيرضرورى كيفيت و انتخاب اقدام بسيار دير، اقدام خيلى زود، اقدام تكرارى، اقدام بسيار كوتاه، اقدام بسيار طولانى، اقدام در توالى تالى اشتباه زمانبندى و توالى

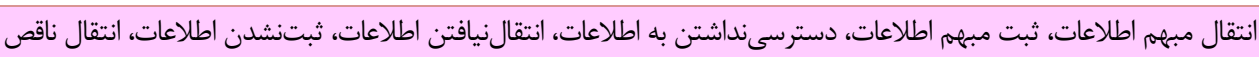

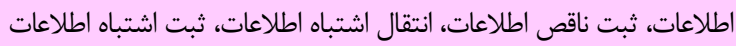

جدول r. طبقدبندى حالت درونى و مكانيسم روانشناختى خطا

\section{مكانيسم روانشناختى خطا}

\begin{tabular}{|c|c|}
\hline & 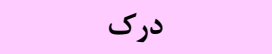 \\
\hline تعصب جانبدارانه & عدمتشخيص بصرى \\
\hline كيجشدن فضايى & ديرتشخيصدادن شنيدارى \\
\hline كيجشدن ادراكى & اشتباهخواندن \\
\hline نقص در اولويتبندى ادراكى & اشتباه دركىردن بصرى \\
\hline تونلزنى ادراكى" & اشتباه شناسايى كردن \\
\hline
\end{tabular}

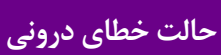

نيناسيىكردن

\footnotetext{
${ }^{2}$ Performance Shaping Factor
}

${ }^{1}$ Psychological error mechanism 


\section{مكانيسم روانشناختى خطا}

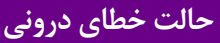

اشباع شدن محركها

عدم شناسايى

$$
\text { نقص هوشيارى }
$$

حواسيرتى/ مشغوليت ذهنى

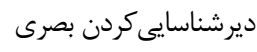

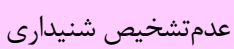

اشتباه شنيدارى

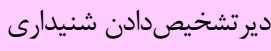

حافظه

\begin{tabular}{|c|c|}
\hline مداخلهُ مشابه & فراموش كردن وظيفه \\
\hline اشباع ظرفيت حافظه & نقص حافظة آيندهنكر \\
\hline انتقال منفى & فراموش كردن اعمال قبلى \\
\hline يادكيرى اشتباه & فراموش كردن اطلاعات موقت \\
\hline 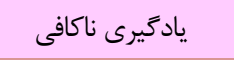 & اشتباه بهيادآوردن اطلاعات موقت \\
\hline 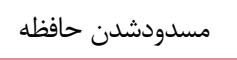 & اشتباه بهيادآوردن اطلاعات ذخيرهشده \\
\hline
\end{tabular}

\section{قضاوت، برنامدريزى، تصميمَيرى}

\begin{tabular}{|c|c|}
\hline 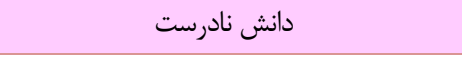 & 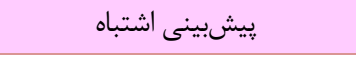 \\
\hline 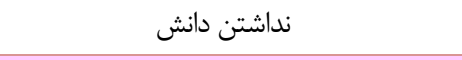 & تصميمَّيرى ضعيف \\
\hline نقص درنظركرفتن تأثيرات درازمدت يا جانبى & ديرتصميمكرفتن \\
\hline اشتباهفهميدن & 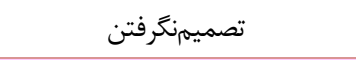 \\
\hline 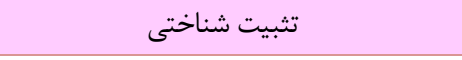 & برنامهريزى ضعيف \\
\hline فرض اشتباه & 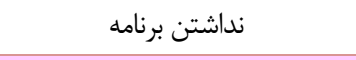 \\
\hline \multicolumn{2}{|l|}{ نقص اولويتبندى } \\
\hline \multicolumn{2}{|l|}{ مردد در تصميهزيرى } \\
\hline & 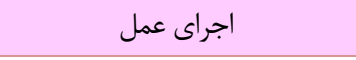 \\
\hline كَيجشدن فضايى & 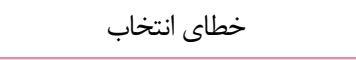 \\
\hline 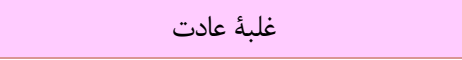 & 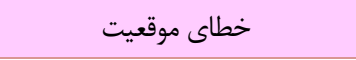 \\
\hline كيجشدن ادراكى & خطاى زمانى \\
\hline كيجشدن كاركردى & اطلاعات غيرواضح انتقال دادهده \\
\hline ل ل لهجهُ نامناسب & اطلاعات غيرواضح ثبتشده \\
\hline افكار منتهى به عمل & اطلاعات نادرست ثبتشده \\
\hline 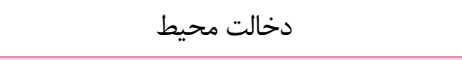 & اطلاعات انتقال دادهنشده \\
\hline حواس يرتى / مشغوليت ذهنى & 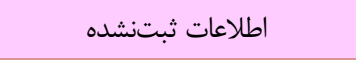 \\
\hline
\end{tabular}

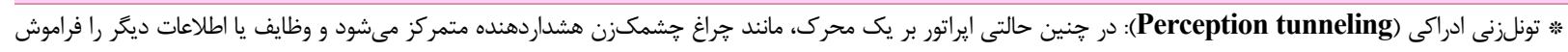


جدول r. فاكتورهاى شكل تيرى عملكرد (PSF)

\begin{tabular}{|c|c|}
\hline توصيف اثر & عوامل \\
\hline آيا دستورالعملى وجود دارد؟ وضوح، يِيحيدگى و تعداد دستور العملها خحكونه است؟ & 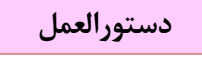 \\
\hline آيا ايراتورها آموزش لازم و تجربأ كافى براى انجاموظيفه را دارند؟ & آموزش و تجربه \\
\hline آيا تعامل ميان انسان- ماشين شفاف و منطقى تعريف شده است؟ & تعامل \\
\hline آيا ايراتور كافى براى انجام كار وجود دارد؟ سيستم ارتباطى؟ پياسخكويى و كار تروهى؟ & 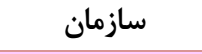 \\
\hline آيا وظيفه، به هوشيارى، تمركز و مهارت ذهنى نياز دارد؟ وظيفهُ محولشده مىتواند سبب خستكى و اضطراب شود؟ & ويزگكىهاى فردى \\
\hline آيا وظيف محولشده، يِيجيدگى بسيارى دارد؟ & ي بيجيدگى وظيفه \\
\hline آيا محيط فيزيكى در اجراى وظيفهُ محولشده تداخل ايجاد مى كند؟ روشنايى محيط؟ خيركى ناشى از پايش & محيط \\
\hline
\end{tabular}

يافته ها

حالت درونى را دارند. در شكل \& درصد خطاى مربوط به درى

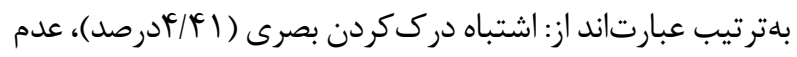

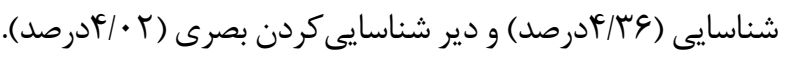
در بخش خطاهاى مربوط به حافظه، بيشترين حالت خطا مربوط به فراموشكردن يك وظيفه با (ه/V9 (درصد) تعيين شدين.

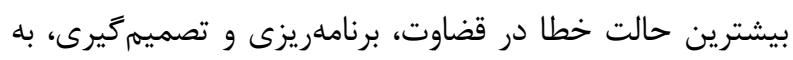

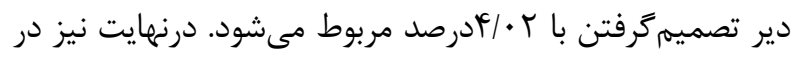
بخش اجرا، خطاى زمانى با N/NY اختصاص داده است.

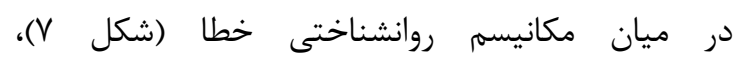

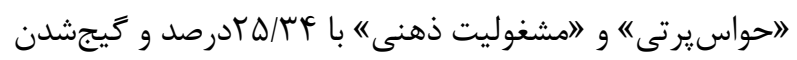

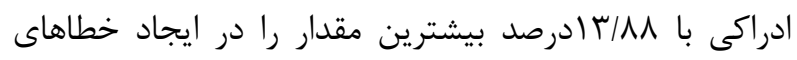

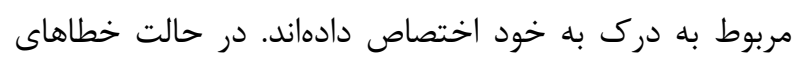
حافظه، بيشترين مقدار مربوط به اشباع ظرفيت حافظه

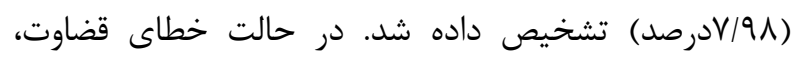

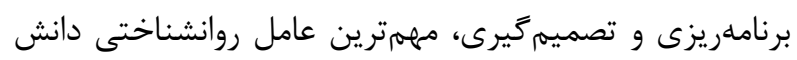

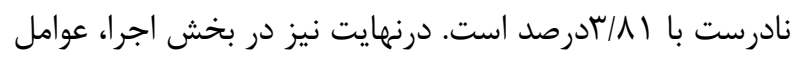

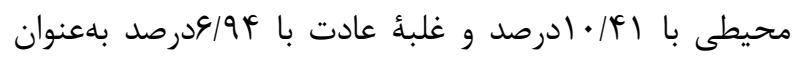
مهممترين عوامل روانشناختى وقوع خطا شناسايى شدند. دربارة فاكتورهاى شكل دهنده عملكرد، كه در شكل 1 نشان داده شده است، بيشترين عامل مربوط به عوامل سازمانى با

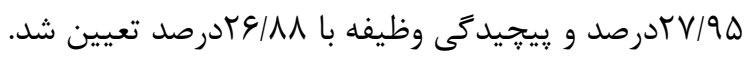

براساس تجزيهوتحليل سلسلهمراتبى وظايف و نظرات ايراتورهاى باتجربه، كا وظيفهُ اصلى و وسا زيروظيفه براى بررسى، مهرم تشخيص داده و انواع خطاهاى مربوط به اين

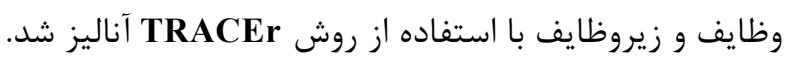

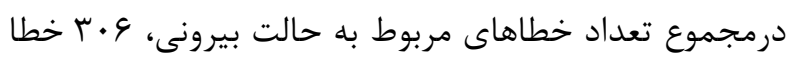

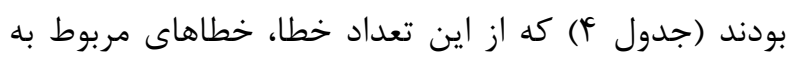

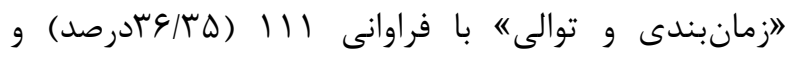

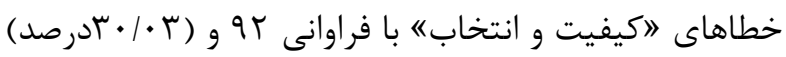
بهترتيب بيشترين و كمترين خطاهاى حالت بيرونى شناخته شدند. باتوجهبه شكل ه، در ميان خطاهاى انتخاب و كيفيت،

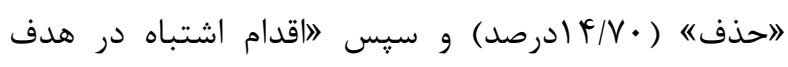
درسته ( (الادر/صد)، بيشترين تعداد خطاها را به خود

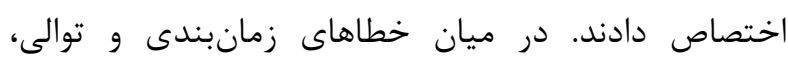

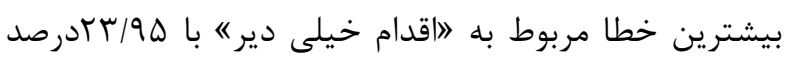
بود. در سومين طبقهبندى، يعنى خطاهاى مربوط به التبادل

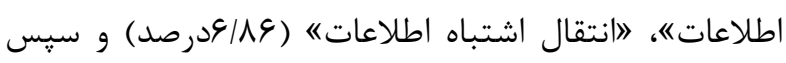

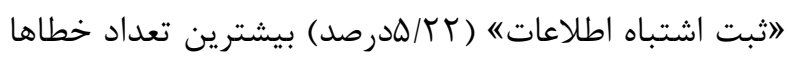
راشتند. خطاهاى حالت بيرونى كه شامل خطاهاى مربوط به درك، حافظه، قضاوت، برنامهريزى و تصميهى گيرى و اجرا مىشود، در

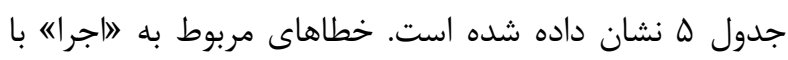

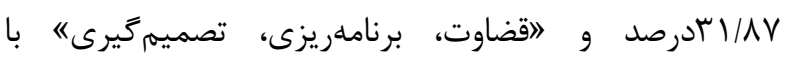

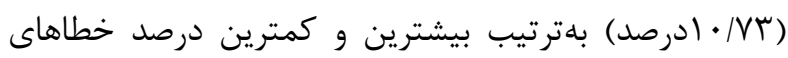




\begin{tabular}{|c|c|c|}
\hline درصد & فراوانى & 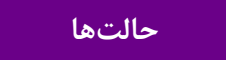 \\
\hline$r \cdot / \cdot r$ & 95 & كيفيت و انتخاب \\
\hline (ب & 111 & زمانبندى و توالى \\
\hline TH/GT & $1 \cdot r$ & تبادل اطلاعات \\
\hline
\end{tabular}

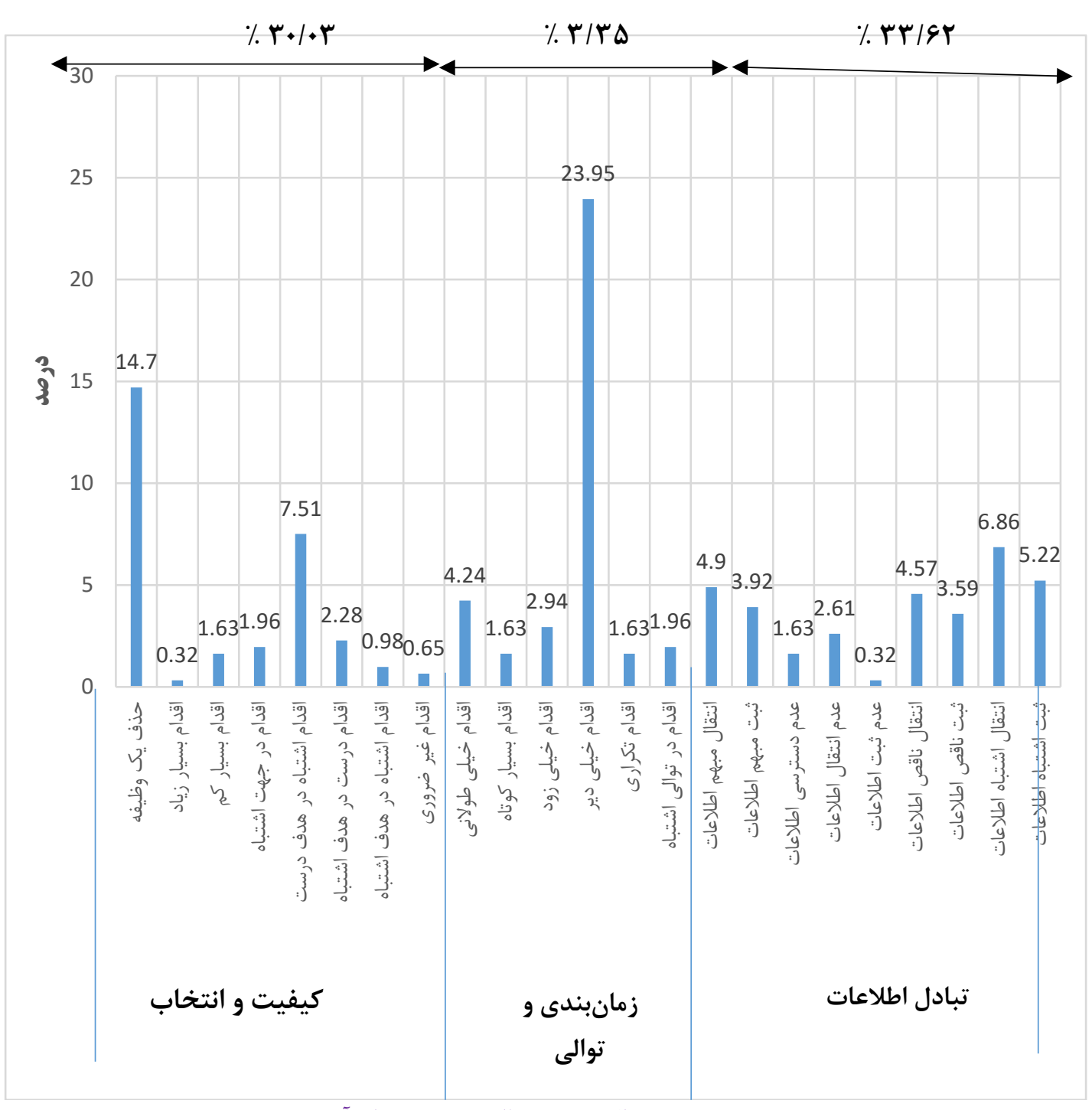

شكل ه. درصد حالت بيرونى خطا و زير مجموعههاى آن 
جدول ه. نتايج حاصل از حالت درونى خطا

\begin{tabular}{|c|c|c|}
\hline درصد & فراوانى & حالتها \\
\hline ५१/^৭ & 19 & درى - م \\
\hline$r V|\Delta|$ & NT & حافظه \\
\hline l./Vr & rt & قضاوت، برنامهريزى و تصميم \\
\hline rl/AV & 90 & اجرا \\
\hline
\end{tabular}

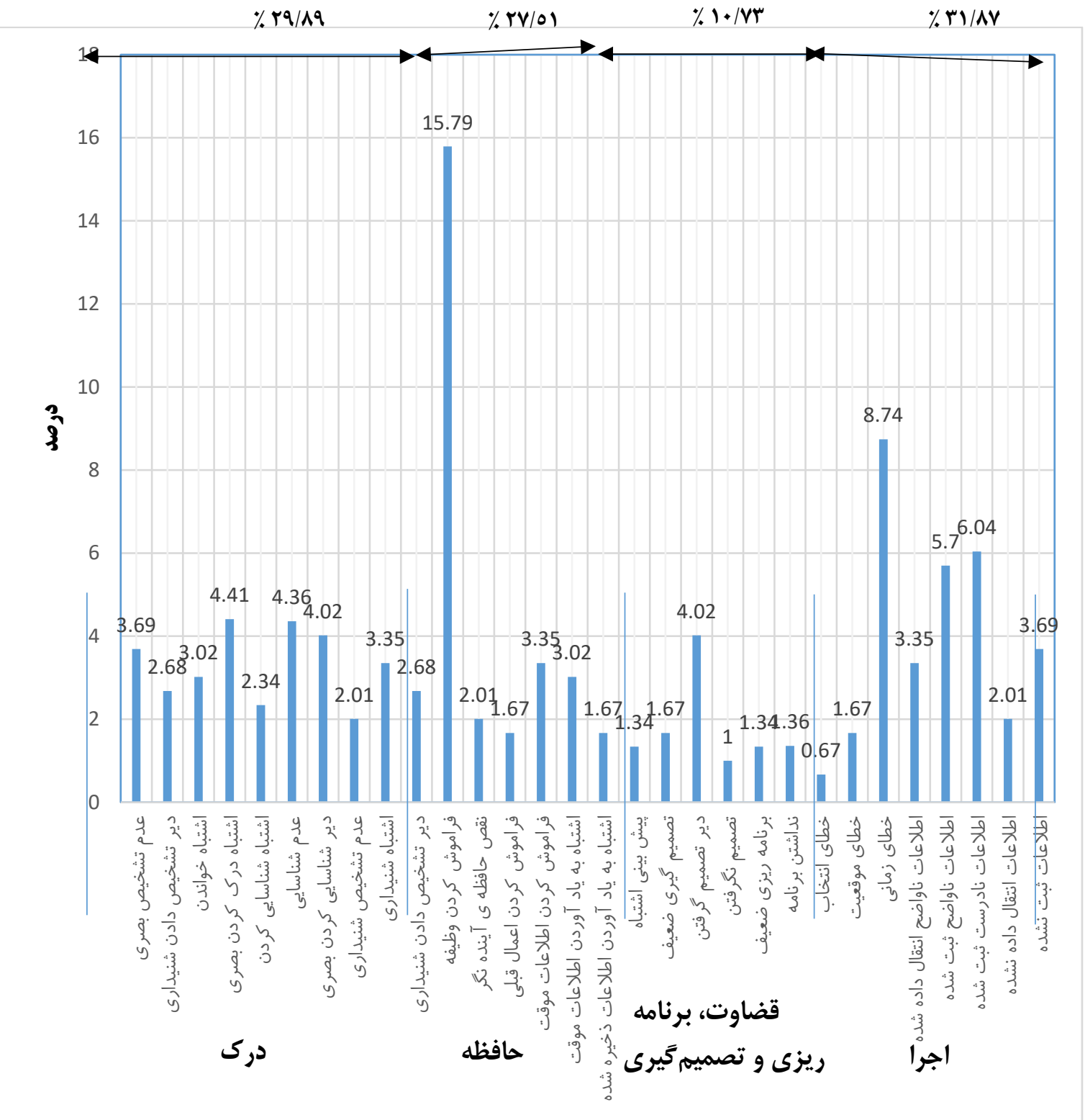

شكل 9. درصد حالت درونى خطا و زيرمجموعههاى آن 


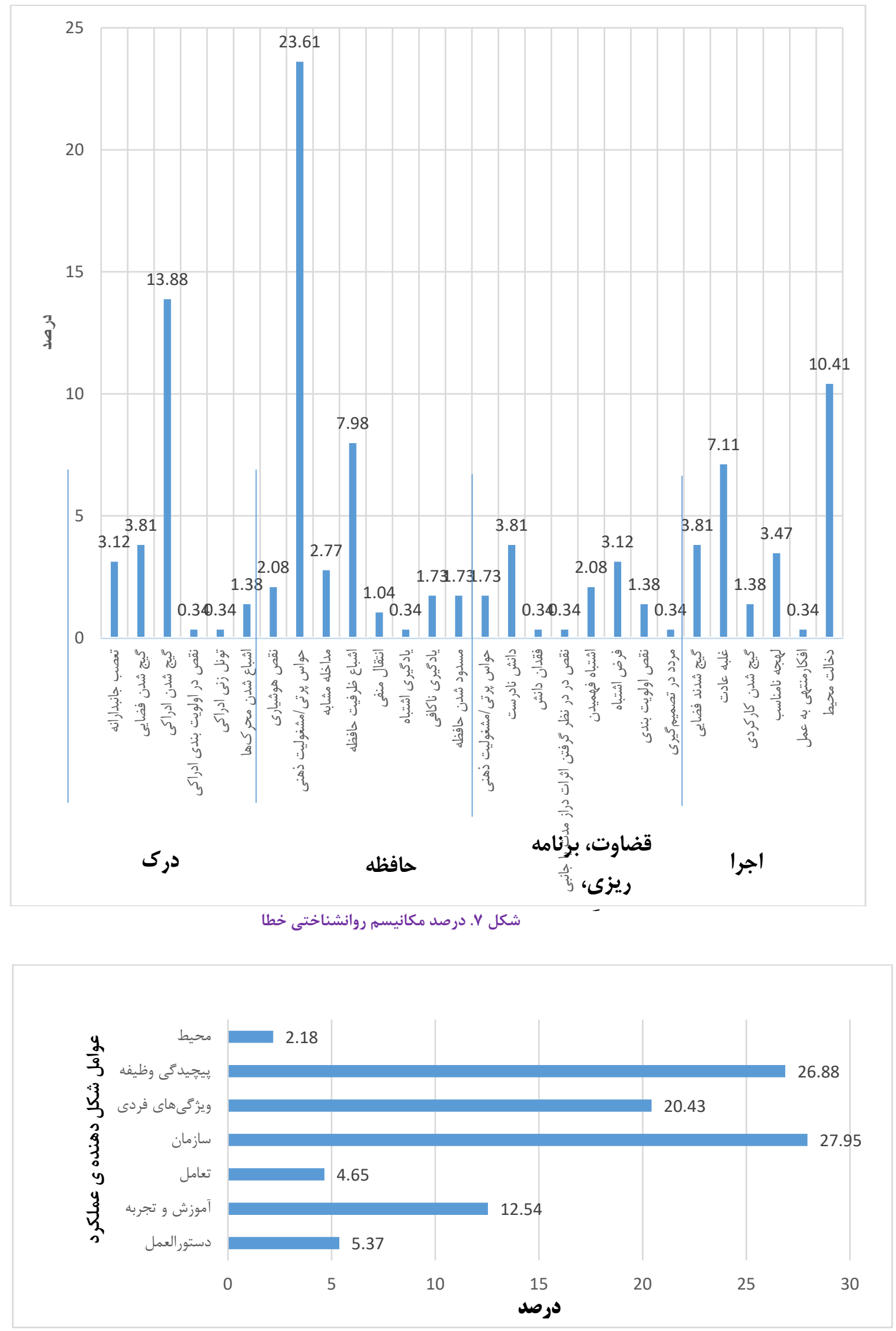

شكل 1. عوامل شكل دهندهُ عملكرد 


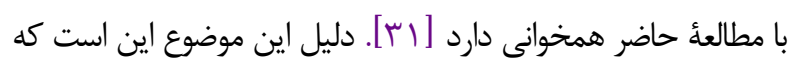

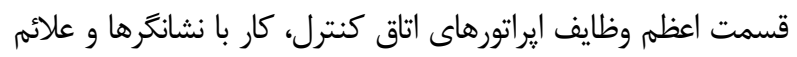
هشداردهنده است؛ درنتيجه بايد مشكلاتى كه در سيستم يا هن: إنكام حادثه رخ مى دهد، در كمترين زمان ممكن شناسايى و درك شود و

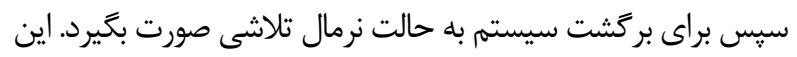

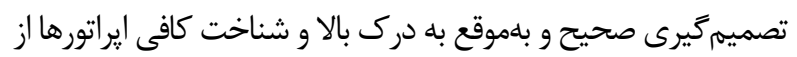
سيستم بستىى دارد. دربارة خطاهاى درك، خطاهاى اشتباه درك كردن بصرى و عدم شناسايى بيشتر مربوط به وظايف جكى دردن

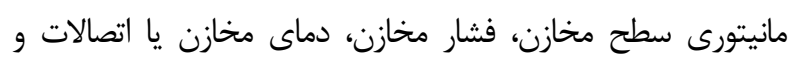

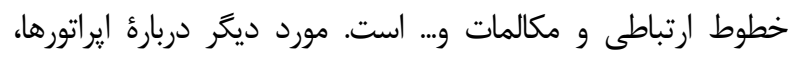

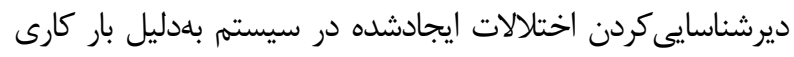
زياد، مشغوليتهاى فكرى و يِيجيد

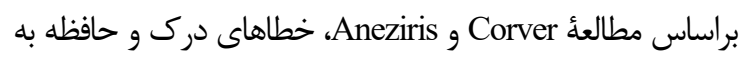

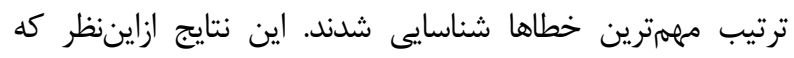

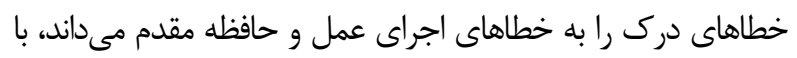

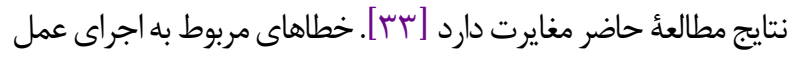

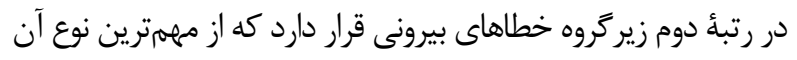

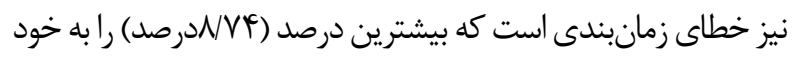

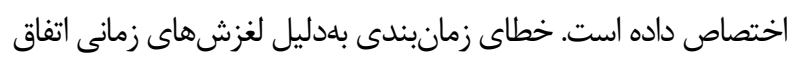

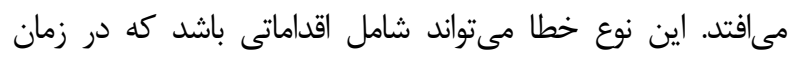

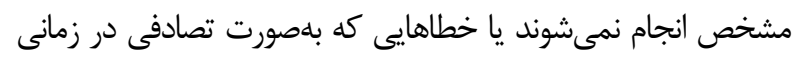

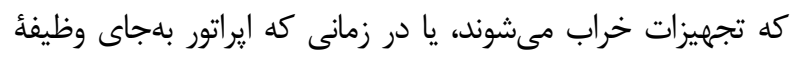

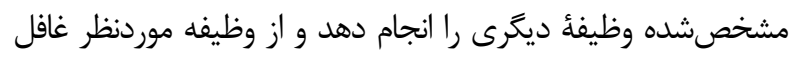

$$
\text { شود، اتفاق مى منتد. }
$$

و و همكاران طى مطالعهاى، با استفاده از تكنيك SHERPA يالايش كاز، نشان مى دهد كه مشهودترين خطاها، خطاهاى عملكردى

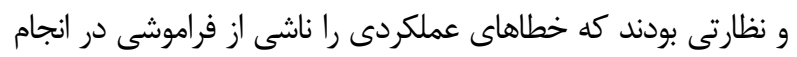

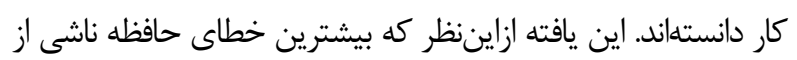

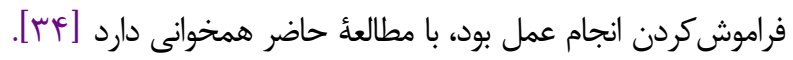
كمتوجهى إيراتور در اجراى برخى وظايف بهدليل مشغولشدن به به ساير وظايف، سبب ايجاد زمينه خطا شده است. همجنين نتايجى مشابه در مطالعة Jones و Endsley بهدستآمده است [هَّ]؛ بلطورىكه

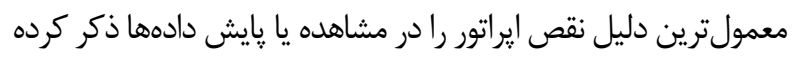

نتايج اين مطالعه دربارة عوامل شكلدهنده عملكرد ايراتورها نشان

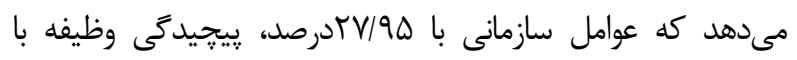

هدف از اين تحقيق آناليز يِيشبينانُٔ خطاهاى شناختى ايراتورهاى

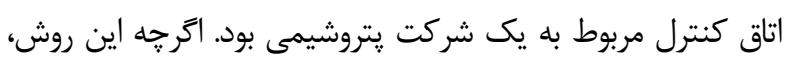

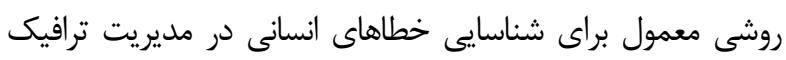

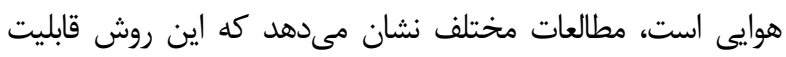

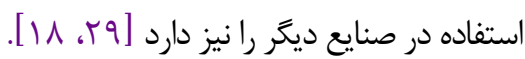

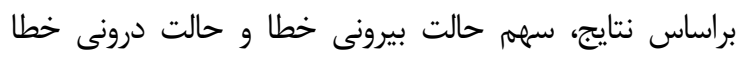

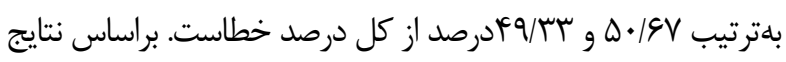

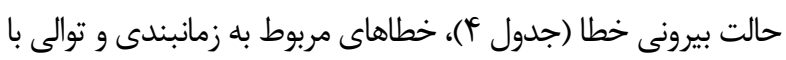

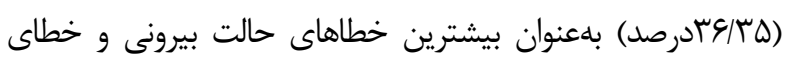

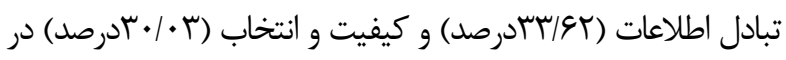

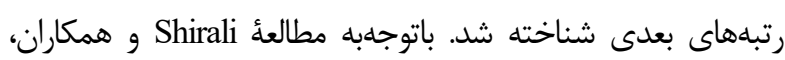

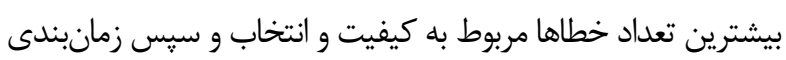
و توالى و درنهايت خطاهاى ارتباطى بود كه با با ين مطالعه مغايرت دارئ دارد.

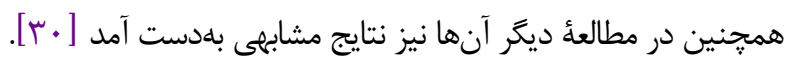

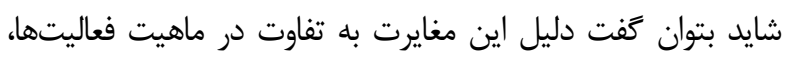

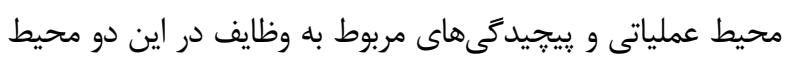
مربوط است. نتايج اين مطالعه در زيرمجموعههاى حالت درونى خطا كه در

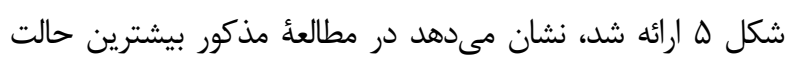

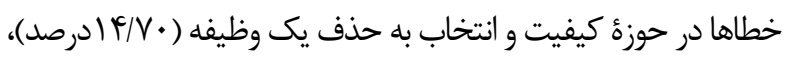
در بخش زمانبندى و توالى به اقدام خيلى دير (هQ

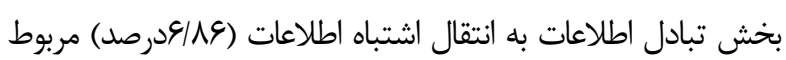

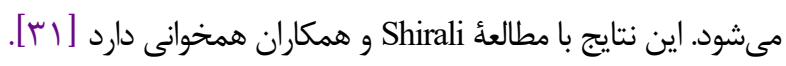

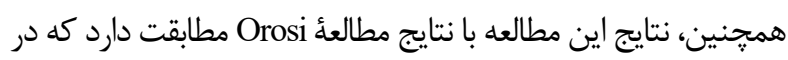

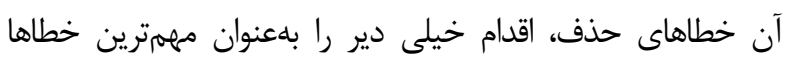

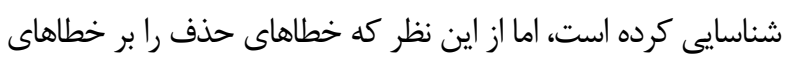

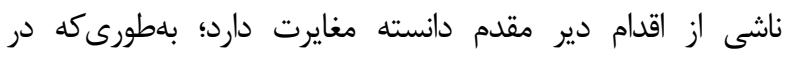

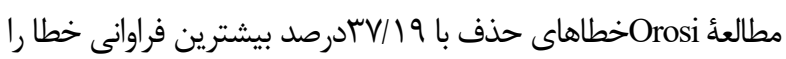

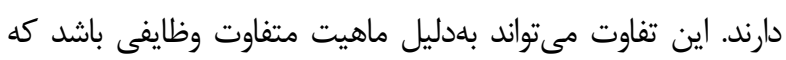

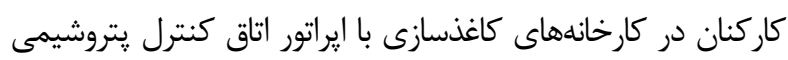

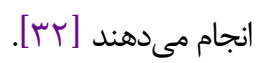
نتايج جدول ه دربارة حالت درونى خطاى ايراتورها نشان مى دهدي،

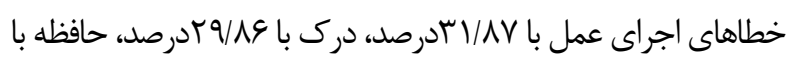
|

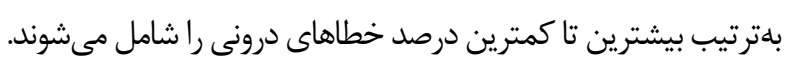

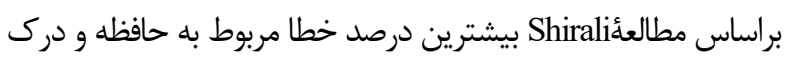
است و ازاينرو كه خطاهاى حافظه را بر خطاهاى درك مقدم مى دئن داند، 
آموزش گيرنده در شرايط حساس را ارزيابى كرده و مهارتهاى

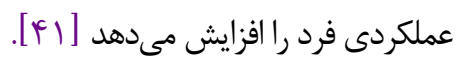

$$
\text { نتيجه گَيرى }
$$

روش TRACEr كه در صنايع كنترل ترافيك هوايى براى طبقهبندى خطاهاى انسانى توسعه يافته است و خطاهايى با ماهيت

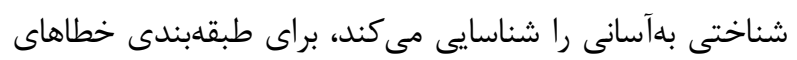
ايراتور اتاق كنترل یتروشيمى و شرايطى كه بر عملكرد ايراتور تأثير

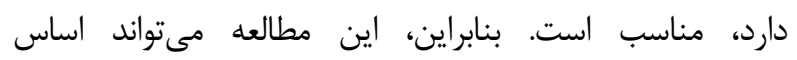
اولويتبندى برنامههاى بيشخيرى از خطاى انسانى در صنايع با بانيا

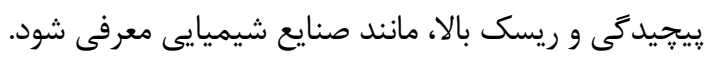

\section{تقدير و تشكر}

اين مقاله مستخرج از طرح يزوهشى با كد اخلاق

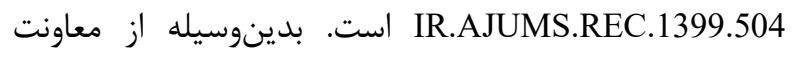

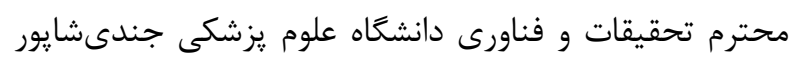
تقدير و تشكر مىشود. همجنين از تمام شركت كنيند مطالعه نيز تقدير و تشكر مىشود.

$$
\text { تعارض منافع }
$$

بين نويسندگان هيجزَنه تعارضى در منافع وجود ندارد.

$$
\text { منابع مالى }
$$

منابع مالى اين مطالعه توسط نويسندكان تامين شده است.

\section{References}

1. Macchi L, Hollnagel E, Leonhard J, editors. Resilience Engineering approach to safety assessment: an application of FRAM for the MSAW system. EUROCONTROL Safety R\&D Seminar; 2009: EUROCONTROL.

2. Hollnagel E. Human Reliability Analysis: Context and Control. 1993. London: Academic Press.

3. Hoseini H. Human Error Engineering: Fanavaran; 2010.

4. Azhdari M, Monazami Tehrani G, Alibabaei A. Investigating the causes of human error-induced incidents in the maintenance operations of petrochemical industry by using HFACS. J. Occup. Hyg. Eng. 2017 Mar 10;3(4):22-30. [DOI:10.21859/johe-03043]

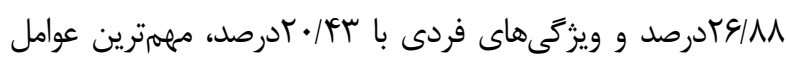

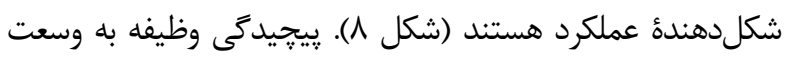
سيستم، تعداد و نوع وظايف اصلى و زيروظايف و تعداد عواملى كه بايد جكى و بررسى شود، وابسته است. براساس مطالعاتى كه در اتاق كنترل

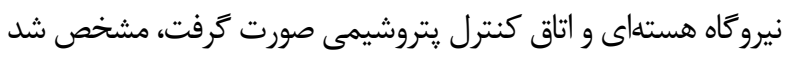
كه يكى از عوامل بحرانى، كه بر عملكرد ايراتورها تأثير گذار بود، تعداد

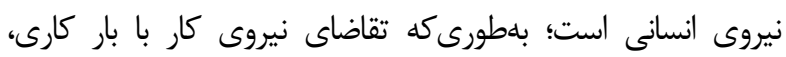

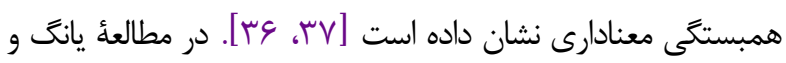
همكاران مشخص شد كه تعداد إيراتورها، عوامل محيطى و ويزگگىهاى

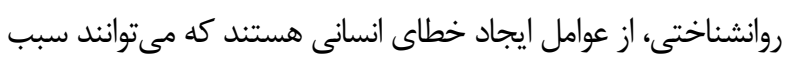

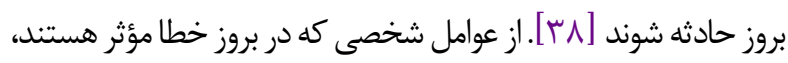
مىتوان به استرس، اضطراب و خستخى اشاره كرد. ايراتورها ساعتها بلهطور مداوم در حال جكى جردن كل سيستم هستند؛ ازاينرو ايجاد حس خستخى امرى طبيعى است. همجنين استرس مى تواند بهدليل حساس و بحرانىبودن وظايف و زيروظايف ايجاد شود. Kirwan، بازخورد ضعيف و بار كارى بالا را دو عامل اصلى بلوجودآورنده خطا

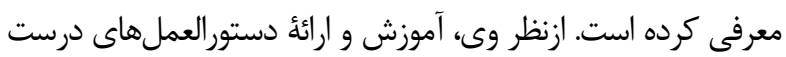

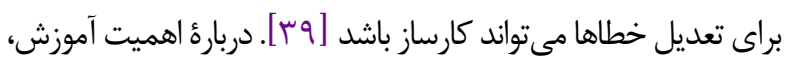
روش هاى شبيهسازى ديجيتالى را بامنظور شناسايى خطاى

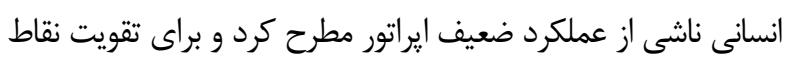

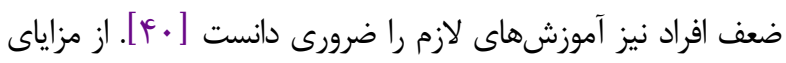
ديگر سيستم شبيهساز اين است كه خطاهاى شناسايىشده را وارد نرمافزار مىكند و با اعمال آنها در جريان آموزش، توانايى سئي

5. Maulana FI, Widyanti A. Adaptation of TracerTechnique for The Retrospective and Predictive Analysis of Cognitive Errors-for Analyzing Indonesian Train Accident Involving Train Dispatcher. InJournal of Physics: Conference Series 2019 Mar 1 (Vol. 1175, No. 1, p. 012193). IOP Publishing. [DOI:10.1088/17426596/1175/1/012193]

6. Khan FI, Abbasi SA. Techniques and methodologies for risk analysis in chemical process industries. J Loss Prev Process Ind. 1998 Jul 1;11(4):261-77. 4230(97)00051-X]

[DOI:10.1016/S0950-

7. Joschek HI. Risk assessment in the chemical industry. In: Proceeding of the international topical meeting on probabilistic risk assessmen. New York, 
NY: American Society of Chemical Engineers. 1981.

8. RG B. Human and organizational factors in safety of engineered systems. In: Conference proceedings for American Society of Safety Engineers Region III and Texas Safety Association. 1998.

9. Jahangiri M, Hoboubi N, Rostamabadi A, Keshavarzi S, Hosseini AA. Human error analysis in a permit to work system: a case study in a chemical plant. Saf Health Work. 2016 Mar 1;7(1):6-11. [DOI:10.1016/j.shaw.2015.06.002] [PMID] [PMCID]

10. International, Association, of, Oil, \&, Gas, et al. Risk assessment data directory. In: International, Association, of, Oil, \&, Gas, et al., editors. Auderghem, Belgium2010.

11. Kirwan B. Human error identification techniques for risk assessment of high risk systems-Part 1: review and evaluation of techniques. Appl. Ergon. 1998 Jun 1;29(3):157-77. [DOI:10.1016/S00036870(98)00010-6]

12. Johan A, Stanton N. Task Analysis (Hardcover).

13. Said MH, Noor MFAM, editors. Technique for the retrospective and predictive analysis of cognitive errors in maritime pilotage operations. 12th international UMT annual symposium" advancements in marine and freshwater sciences; 2013.

14. Shorrock ST, Kirwan B. Development and application of a human error identification tool for air traffic control. Appl. Ergon. 2002 Jul 1;33(4):319-36.

[DOI:10.1016/S00036870(02)00010-8]

15. Shorrock ST. Errors of perception in air traffic control. Saf. Sci. 2007 Oct 1;45(8):890-904. [DOI:10.1016/j.ssci.2006.08.018]

16. Shorrock ST. Errors of memory in air traffic control. Saf. Sci. 2005 Oct 1;43(8):571-88. [DOI:10.1016/j.ssci.2005.04.001]

17. Theophilus SC, Ekpenyong IE, Ifelebuegu AO, Arewa AO, Agyekum-Mensah G, Ajare TO. A technique for the retrospective and predictive analysis of cognitive errors for the oil and gas industry (TRACEr-OGI). Saf. Sci. 2017 Dec; 3(4):23. [DOI:10.3390/safety3040023]

18. Baysari MT, Caponecchia C, McIntosh AS. A reliability and usability study of TRACEr-RAV: The technique for the retrospective analysis of cognitive errors-For rail, Australian version. Appl. Ergon. $2011 \quad$ Nov 1;42(6):852-9. [DOI:10.1016/i.apergo.2011.01.009] [PMID]
19. Shirali G, Hosseinzadeh T, Dibeh Khosravi A, Rasi H, Moradi MS, Karami E, Fathi A, Rezaei M, Barzegar L. Integration of human information processing model and SHERPA technique in the analysis of human errors: A Case Study in the control room for the petrochemical industry. Iran Occup. Health. 2017 Apr 10;14(1):1-1.

20. Petrillo A, Falcone D, De Felice F, Zomparelli F. Development of a risk analysis model to evaluate human error in industrial plants and in critical infrastructures. Int. J. Disaster Risk Reduct. 2017 Aug 1;23:15-24. [DOI:10.1016/j.ijdrr.2017.03.012]

21. Ghasemi M, Nasleseraji J, Hoseinabadi S, Zare M. Application of SHERPA to identify and prevent human errors in control units of petrochemical industry. Int J Occup Saf Ergon. 2013 Jan $1 ; 19(2): 203-9$.

[DOI:10.1080/10803548.2013.11076979] [PMID]

22. Ghasemi M, Saraji G, Zakerian A, Azhdari MR. Control of human errors and comparison of risk levels after correction action with the SHERPA method in a control room of petrochemical industry. Iran Occup. Health. 2011 Oct 1;8(3).

23. Shokria S. A Cognitive Human Error Analysis with CREAM in Control Room of Petrochemical Industry. Biotech. Health. Sci. 2017(1):13-21. [DOI:10.5812/bhs-38592]

24. Maddah S, Ghasemi M. Estimating the human error probability using the fuzzy logic approach of CREAM (The case of a control room in a petrochemical industry). Organization.;4:0-100.

25. Ghalenoei M, Asilian H, Mortazavi S, Varmazyar S. Human error analysis among petrochemical plant control room operators with human error assessment and reduction technique. Iran Occup. Health. 2009 Jul 25;6(2):38-50.

26. Sandom C, Harvey RS, editors. Human factors for engineers. Iet; 2004 Aug 13. [DOI:10.1049/PBNS032E]

27. Swain AD, Guttmann HE. Handbook of humanreliability analysis with emphasis on nuclear power plant applications. Final report. Sandia National Labs.; 1983. [DOI:10.2172/5752058]

28. Isaac A, Shorrock ST, Kirwan B. Human error in European air traffic management: the HERA project. Reliab. Eng. Syst. Saf. 2002 Feb 1;75(2):257-72. [DOI:10.1016/S09518320(01)00099-0]

29. Cheng CM, Hwang SL. Applications of integrated human error identification techniques on the chemical cylinder change task. Appl. Ergon. 2015 
Mar

$1 ; 47: 274-84$

[DOI:10.1016/j.apergo.2014.10.008] [PMID]

30. Abbas Shirali G, Malekzadeh M. Classification and quantification of human error in air traffic control: a case study in an airport control tower. Int J Occup Saf Ergon. 2020 Aug 27:1-3. [DOI:10.1080/10803548.2020.1760526] [PMID]

31. Shirali GA, Malekzadeh M. Predictive Analysis of Controllers' Cognitive Errors Using the TRACEr Technique: A Case Study in an Airport Control Tower. Jundishapur. J. Health. Sci. 2016;8(2). [DOI:10.17795/jjhs-34268]

32. Orosi M, Mombeni B. Assessment of human errors in paper machines of pars paper industrial group by Predictive Human Error Analysis (PHEA). Jundishapur. J. Health. Sci. 2012 Dec 31;4(4).

33. Corver SC, Aneziris ON. The impact of controller support tools in enroute air traffic control on cognitive error modes: A comparative analysis in two operational environments. Saf. Sci. 2015 Jan 1;71:2-15. [DOI:10.1016/j.ssci.2014.07.018]

34. Halvani G, Mehrparvar AH, Shamsi F, Rafieenia R, Khani Mouseloo B, Ebrahimi G. Risk assessment of human error among Mohr City, Parsian Gas refinery company control room operators using systematic human error reduction and prediction approach SHERPA in 2016. Occup Med (Lond). 2017 Jul 10;9(3):32-44.

35. 35Jones DG, Endsley MR. Sources of situation awareness errors in aviation. Aviation, space, and environmental medicine. 1996 Jun.

36. Lin CJ, Yenn TC, Jou YT, Hsieh TL, Yang CW. Analyzing the staffing and workload in the main control room of the advanced nuclear power plant from the human information processing perspective. Saf. Sci. 2013 Aug 1;57:161-8. [DOI:10.1016/j.ssci.2013.02.004]

37. Shirali G, Dibeh Khosravi A, Hosseinzadeh T, Fathi A, Hame Rezaee M, Hamzeiyan Ziariani M. Using the human information-processing model and workload to predict staffing demand: A case study in a petrochemical control room. Iran J Ergon. 2014 Dec 10;2(3):70-6.

38. Lane R, Stanton NA, Harrison D. Applying hierarchical task analysis to medication administration errors. Applied ergonomics. 2006 Sep 1;37(5):669-79. [DOI:10.1016/j.apergo.2005.08.001] [PMID]

39. Kirwan B, Scannali S, Robinson L. A case study of a human reliability assessment for an existing nuclear power plant. Appl. Ergon. 1996 Oct
1;27(5):289-302.

6870(96)00014-2]

[DOI:10.1016/0003-

40. 40Sikorski M. Use of digital simulation in reliability analysis for the design of industrial process control systems. Reliab. Eng. Syst. Saf. 1991 Jan 1;31(3):281-95. [DOI:10.1016/09518320(91)90072-F]

41. Grozdanović M, Stojiljković E. Framework for human error quantification. FU Phil Soc Psy Hist. 2006;5(1):131-44. 